Document downloaded from:

http://hdl.handle.net/10251/166537

This paper must be cited as:

Daliran, S.; Ghazagh-Miri, M.; Oveisi, AR.; Khajeh, M.; Navalón Oltra, S.; Alvaro Rodríguez, MM.; Ghaffari-Moghaddam, M.... (2020). A Pyridyltriazol Functionalized Zirconium MetalOrganic Framework for Selective and Highly Efficient Adsorption of Palladium. ACS Applied Materials \& Interfaces. 12(22):25221-25232. https://doi.org/10.1021/acsami.0c06672

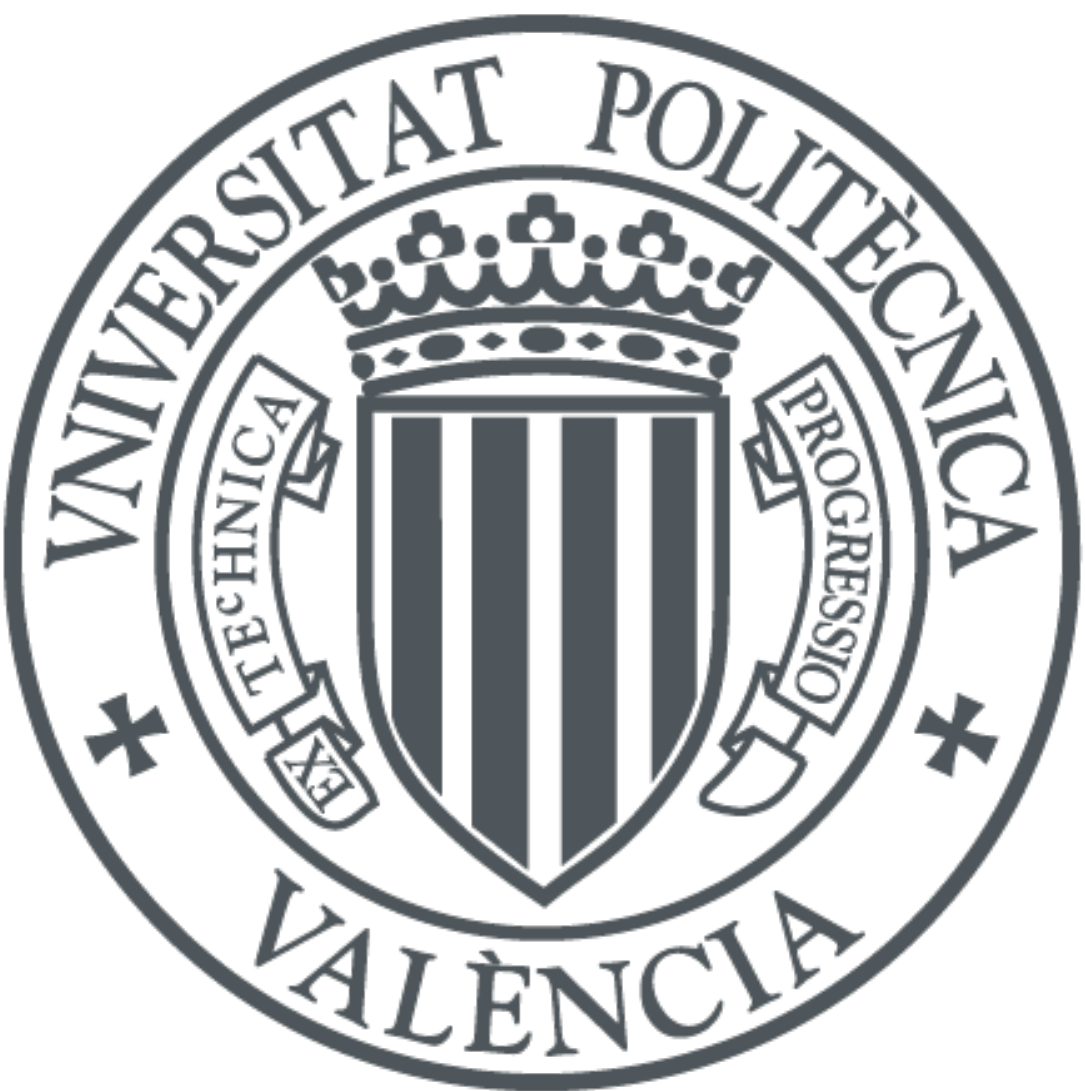

The final publication is available at

https://doi.org/10.1021/acsami.0c06672

Copyright American Chemical Society

Additional Information 


\section{A Pyridyltriazol Functionalized Zirconium Metal- Organic Framework for Selective and Highly Efficient Adsorption of Palladium}

Saba Daliran, ${ }^{a, b, c}$ Mahbobeh Ghazagh-Miri, ${ }^{a}$ Ali Reza Oveisi, ${ }^{a}{ }_{*}$ Mostafa Khajeh, ${ }^{a}{ }_{*}$ Sergio Navalón, ${ }^{b}$ Mercedes Álvaro, ${ }^{b}$ Mansour Ghaffari-Moghaddam, ${ }^{a}$ Hojat Samareh Delarami, ${ }^{a}$ and Hermenegildo García ${ }^{b, d, *}$

\section{AUTHOR ADDRESS}

${ }^{a}$ Department of Chemistry, University of Zabol, P.O. Box: 98615-538, Zabol, Iran

b Departamento de Química and Instituto de Tecnología Química CSIC-UPV, Universidad Politécnica de Valencia, Av. de los Naranjos s/n, 46022 Valencia, Spain

${ }^{\text {c }}$ Faculty of Chemistry, Bu-Ali Sina University, P.O. Box: 6517838683, Hamedan, Iran

d Center of Excellence for Advanced Materials Research, King Abdulaziz University, Jeddah, Saudi Arabia 


\section{ABSTRACT}

This work reports the synthesis of pyridyltriazol-functionalized UiO-66 (UiO stands for University of Oslo), namely $\mathrm{UiO}-66-\mathrm{Pyta}$, from $\mathrm{UiO}-66-\mathrm{NH}_{2}$ through three post-synthetic modification (PSM) steps. The good performance of the material derives from the observation that partial formylation ( 21\% of $-\mathrm{NHCHO}$ groups) of $\mathrm{H}_{2} \mathrm{BDC}-\mathrm{NH}_{2}$ by DMF, as persistent impurity, takes place during synthesis of the UiO-66- $\mathrm{NH}_{2}$. Thus, to enhance material performance, firstly, the as-synthesized $\mathrm{UiO}-66-\mathrm{NH}_{2}$ was deformylated to give pure UiO-66$\mathrm{NH}_{2}$. Subsequently, the pure UiO-66- $\mathrm{NH}_{2}$ was converted to UiO-66- $\mathrm{N}_{3}$ with nearly complete conversion ( 95 \%). Finally, the azide-alkyne[3+2]-cycloaddition reaction of 2-ethynylpyridine with the UiO-66- $\mathrm{N}_{3}$ gave the UiO-66-Pyta. The porous MOF was then applied for the solidphase extraction of palladium ions from aqueous medium. Affecting parameters on extraction efficiency of $\mathrm{Pd}(\mathrm{II})$ ions were also investigated and optimized. Interestingly, UiO-66-Pyta exhibited selective and superior adsorption capacity for Pd(II) with maximum sorption capacity of $294.1 \mathrm{mg} \mathrm{g}^{-1}$ at acidic $\mathrm{pH}$ (4.5). The limit of detection (LOD) was found to be $1.9 \mu \mathrm{g} \mathrm{L}^{-1}$. The estimated intra-day and inter-day precisions are $3.6 \%$ and $1.7 \%$, respectively. Moreover, the adsorbent was regenerated and reused for 5 cycles without any significant change in the capacity and repeatability. The adsorption mechanism was described based on various techniques such as FT-IR, PXRD, SEM/EDS, ICP-AES, and XPS analyses as well as density functional theory (DFT) calculations. Notably, as a case study, the obtained UiO-66-Pyta after palladium adsorption, UiO-66-Pyta-Pd, was used as an efficient catalyst for Suzuki-Miyaura cross-coupling reaction. 
KEYWORDS Zirconium Metal-organic framework, UiO-66- $\mathrm{NH}_{2}$, Pyta-functionalized Zr-MOF, Heavy metal adsorption, Extraction, Density functional theory, Post-synthetic modification, Heterogeneous catalysis, Palladium 


\section{Introduction}

Owing to its unique properties, palladium is increasingly used in research laboratories and industrial technologies including catalysis, electronics, pharmaceutics, and corrosion protection. $^{1-3}$ Also, platinum group metals (PGMs) find extensive utility as automotive exhaust catalysts. ${ }^{1,4}$ However, the use of palladium has important limitations, such as high-cost, toxicity at higher concentrations, and limited availability of natural resource ${ }^{1}$. Various technologies for the recovery of $\mathrm{Pd}(\mathrm{II})$ including liquid phase extraction, ${ }^{5}$ membrane filtration, ${ }^{6}$ and ion exchange $^{7}$ have been reported. These methods suffer from some drawbacks such as the incomplete recovery, generation of high volumes of wastes, high costs and labor requirements and less selectivity. Solid-phase extraction (SPE) is known as an economical and effective strategy for the recovery of metal species, ${ }^{8-10}$ because of its low cost, simplicity, selectivity improvement, and less usage of organic solvents. Up to now, most precedents have been focused on chitosan, ${ }^{11,12}$ graphene oxide, ${ }^{13}$ functionalized mesoporous silica, ${ }^{14}$ and ionic liquid-SBA- $15^{15}$ as adsorbents for recovery of palladium. However, from the viewpoint of economics and environment control, the introduction of effective approaches/adsorbents for extracting and recovery of this valuable metal is still necessary. ${ }^{3,16}$ Metal-organic frameworks (MOFs) as new generation of porous materials, are 3D crystalline and low-dense structures constructed from inorganic nodes and organic ligands. ${ }^{17-19}$ MOFs can be rationally pre-designed and synthesized to have very high surface area, high porosity (pore size values ranging from a few angstroms to several nanometers), high stability, and unique properties. ${ }^{18}$ Using post-synthetic modification (PSM) reactions on MOFs, it is possible to introduce new functional groups into the MOF lattice after its formation, tuning precisely the chemical and physical properties, allowing the obtainment of the desired materials. ${ }^{20,21}$ As a result, MOFs have attracted considerable attention 
for their important applications in various areas such as gas storage and separation, ${ }^{17,}{ }^{22,} 23$ chemical catalysis and photocatalysis, ${ }^{24-27}$ drug delivery, ${ }^{28}$ and removal of toxic chemicals. ${ }^{29,} 30$ Zr-containing MOFs are one of the most widely used class of MOF materials due to their high chemical, thermal, and mechanical stability as well as their relatively low-toxicity. ${ }^{31,32}$ The high stability derives from the strong interaction of highly oxophilic $\operatorname{Zr}(\mathrm{IV})$ sites with negatively charged carboxylate linkers. The large accessible surface area and porosity of MOFs permits easy diffusion of ions/molecules within the 3D framework, thereby, improving the adsorption performance of these materials. As a result, a series zirconium MOFs have been used as adsorbents for removal of uranium, ${ }^{33}$ selenium, ${ }^{34,}{ }^{35}$ arsenic, ${ }^{36}$ and other metal ions. ${ }^{37}$ The adsorption performance mainly derives from interactions between target ions and $\mathrm{Zr}$-nodes associated with the unique high surface area and highly ordered structures of the MOFs.

It has been demonstrated that the efficiency, selectivity, and adsorption capacity of a MOF towards ion metals are also largely influenced by the presence of substituents on the organic linkers, ${ }^{37,} 38$ resulted from replacement terephthalic acid in the parent MOF by substituted terephthalic acid ${ }^{23,34,38-41}$ or modifying of MOFs by post-synthetic strategies. ${ }^{8,42-44}$ For example, the post-modification of UiO-66- $\mathrm{NH}_{2}$ by resorcyl aldehyde via an imine formation was reported for the selective adsorption of lead ions in aqueous media with a maximum

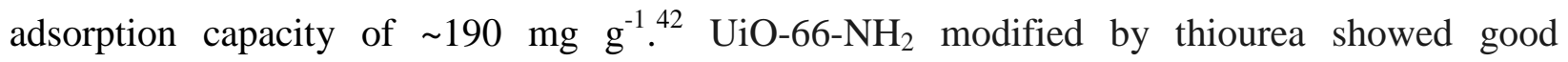
adsorption capacity of $117 \mathrm{mg} \mathrm{g}^{-1}$ and $232 \mathrm{mg} \mathrm{g}^{-1}$, respectively, for the removal of Cd(II) and $\mathrm{Pb}(\mathrm{II})$, performing better than the parent UiO-66- $\mathrm{NH}_{2}$ MOF. ${ }^{43}$ The ASUiO-66 MOF (AS: allylsulfanyl) was used for the extraction of Pd(II), revealing a low saturation capacity of 45.4 $\mathrm{mg} \mathrm{g}^{-1} \cdot{ }^{23}$ Very recently, the MOF-808 has been post-synthetically modified with ethylenediaminetetraacetic acid (EDTA), as a chelating group, and the sorbent exhibited non- 
specific high affinity toward 22 kinds of metal ions covering soft acids (such as palladium), hard acids, and borderline acids. ${ }^{44}$

However, the introduction of new and specific functional groups/ligands into MOFs providing high selectivity, rapid adsorption rate, and high adsorption capacity for transition metals such as palladium ions is highly demanded.

Recently, pyridine-triazole ligands have emerged as promising ligands for the recovery of $\mathrm{Pd}(\mathrm{II}) .{ }^{45,}{ }^{46} \mathrm{Pd}$ coordination to the pyridyl nitrogen and the medial nitrogen of the triazole ring was observed for these complexes, according to the X-ray crystallographic analyses.

Based on the precedents mentioned above, we anticipated that a robust, porous MOFcontaining pyridine-triazole functional group could be a suitable material for the SPE of Pd(II). Therefore, a MOF material involving pyridyltriazol ligand named as UiO-66-Pyta (Pyta: pyridyltriazol) was designed through a three-step sequential modification process, starting from a robust $\mathrm{Zr}-\mathrm{MOF}$, UiO-66- $\mathrm{NH}_{2}$. The Pyta-functionalized MOF was then applied as an efficient sorbent for the SPE of palladium from aqueous solutions. To the best of our knowledge, precedents have neglected hydrolysis of formamide groups prior to PSM of amino-functionalized UiO-66 MOF. This work demonstrates the PSM of MOFs for rapid, selective, and highly efficient capture of palladium ions. Interestingly, the UiO-66-Pyta MOF after adsorption of Pd is converted into an efficient and reusable catalyst for Suzuki-Miyaura cross-coupling reaction, which is an innovative example for making waste-to-treasure.

\section{Experimental Section}

\subsection{Materials}


All reagents and solvents were purchased from commercial sources and were used as received, unless noted otherwise. Zirconium chloride $\left(\mathrm{ZrCl}_{4},>99.5 \%\right)$, 2-aminoterephthalic acid, azidotrimethylsilane (( $\left.\mathrm{CH}_{3}\right)_{3} \mathrm{Si}-\mathrm{N}_{3}$, TMS- ${ }_{3}$, 95\%), tert-butyl nitrite (( $\left.{ }^{\mathrm{t}} \mathrm{Bu}-\mathrm{ONO}, 90 \%\right)$, methanol ( $\left.\mathrm{CH}_{3} \mathrm{OH}\right)$, 2-ethynylpyridine, hydrofluoric acid (HFaq 47-51\%), chloroform $\left(\mathrm{CHCl}_{3}\right.$, puriss. p.a., > 99\%), and silica gel (Sorbent Technologies, $60 \AA$, 40-63 $\mu \mathrm{m}$ ) were obtained from commercial sources (Sigma-Aldrich, Germany) and used as received. Dichloromethane (DCM) was distilled and stored over molecular sieves (4 $\AA$ ) under an atmosphere of argon. All thin layer chromatography (TLC) analyses were performed on TLC Silica gel 60 RP-18 F254S plates with aluminium sheets (Merck KGaA, Germany). UiO-66 was prepared from terephthalic acid instead of 2-aminoterephthalic acid based on the literature procedure. ${ }^{47}$

\subsection{Characterization}

${ }^{1} \mathrm{H}$ NMR spectra were recorded on a Bruker (Germany) Avance $400 \mathrm{MHz}(399.49 \mathrm{MHz}$ for ${ }^{1} \mathrm{H}$ ) spectrometer at ambient temperature in DMSO-d $/$ /HFaq mixture. The sample (ca. $2 \mathrm{mg}$ ) was digested with sonication in DMSO- $d_{6}$ containing small amounts of hydrofluoric acid (5-10 $\mu 1$ of HFaq in $700 \mu 1$ of DMSO- $d_{6}$ ) and the resulting solution was analyzed by ${ }^{1} \mathrm{H}$ NMR spectroscopy. ${ }^{1} \mathrm{H}$ chemical shifts are referenced to the residual proton resonance of solvent on the $\delta$ scale. Caution: Aqueous HF is toxic and corrosive. Inhalation and contact with skin and eyes must be avoided. Powder X-ray diffraction (PXRD) patterns were collected on a Philips Xpert diffractometer (Amsterdam, The Netherlands) with monochromated $\mathrm{Cu} K \alpha$ radiation $(\lambda=1.5418$ $\AA$ ) within the range of $1.5^{\circ}<2 \theta<50^{\circ}$. Fourier-transform infrared (FT-IR) spectra were recorded in the range $500-4000 \mathrm{~cm}^{-1}$ using $\mathrm{KBr}$ pellets on a Perkin Elmer Spectrum-FTIR Version 10.01.00 (USA). The morphology of the samples was characterized using scanning electron 
microscopy (SEM, MIRA3 TESCAN, Czech Republic). The $\mathrm{N}_{2}$ adsorption isotherms at $77 \mathrm{~K}$ were measured using an ASAP 2010 Micrometrics Instrument Corp., USA. The samples were degassed in vacuum at $120^{\circ} \mathrm{C}$ for $12 \mathrm{~h}$ and then measured at $77 \mathrm{~K}$. The data were analyzed using the TriStar II 3020 V1.03 software (Micromeritics, Norcross, GA). The determination of analyte in solution was done by UV-Vis spectrophotometer (UV-2100 RAY Leigh, Beijing, China) in maximum wavelength $(410 \mathrm{~nm})$. The $\mathrm{pH}$ meter model 630 Metrohm combined with glass electrode was used for measurement of solution $\mathrm{pH}$. The Zeta potential of the samples was determined by dynamic light scattering (DLS) measurements at $25{ }^{\circ} \mathrm{C}$ after dispersion in aqueous medium at different $\mathrm{pH}$ values. X-ray photoelectron spectra (XPS) of the solid prepared was collected on a SPECS spectrometer with a MCD-9 detector using a monochromatic $\mathrm{Al}(\mathrm{Ka}=$ $1486.6 \mathrm{eV}$ ) X-ray source (Germany). Thermogravimetric analysis (TGA) were measured on a Mettler Toledo TGADSC under $\mathrm{N}_{2}$ atmosphere. GC-MS analysis was carried out on a computerinterfaced Agilent Technologies 6890 Network instrument equipped with an Agilent 5973 Network mass-selective detector (USA). The column used was a 30-m HP-5 capillary column $(30 \mathrm{~m} \times 0.320 \mathrm{~mm} \times 0.25 \mu \mathrm{m}$ film thickness $)$ with Flow rate $=0.9 \mathrm{~mL} / \mathrm{min}$.

\subsection{Synthesis of MOFs}

Synthesis of $\mathrm{UiO}-66-\mathrm{NH}_{2}$

UiO-66- $\mathrm{NH}_{2}$ was synthesized according to the procedure reported by Corma and coworkers. $^{47}$

Preparation of pure UiO-66- $\mathrm{NH}_{2}$ 
The as-synthesized UiO-66- $\mathrm{NH}_{2}(500 \mathrm{mg}$ ) was refluxed in methanol (50 mL) for $24 \mathrm{~h}$. The solid was filtered off and washed with methanol. The sample was then dried at room temperature under vacuum and by heating to $100{ }^{\circ} \mathrm{C}$ under vacuum for $2 \mathrm{~h}$ in an oven to give the pure UiO-66- $\mathrm{NH}_{2}$ (deprotected $\mathrm{Zr}-\mathrm{MOF}$ ). This MOF was used in the next step. The sample was activated under dynamic vacuum at $150{ }^{\circ} \mathrm{C}$ for $12 \mathrm{~h}$. Prior to $\mathrm{N}_{2}$ isotherm measurements, the activation process was required.

Synthesis of azide-functionalized (UiO-66- $\left.\mathrm{N}_{3}\right)$

Freshly dried UiO-66- $\mathrm{NH}_{2}$ (100 mg, $0.342 \mathrm{mmol}$ of $-\mathrm{NH}_{2}$ ) was suspended in THF (4.0 $\mathrm{mL})$ in a glass vial $(\sim 12 \mathrm{~mL})$. The vial was placed in an ice bath and $t$-BuONO (1.94 mL, 16.42 mmol, 48 eq) was added and stirred followed by adding $\mathrm{TMSN}_{3}(1.70 \mathrm{~mL}, 12.99 \mathrm{mmol}, 38 \mathrm{eq})$ to the resulting mixture over $5 \mathrm{~min}$. The reaction was stirred for $6 \mathrm{~h}$ at room temperature before being quenched by decanting the solvent after centrifugation. Excess reactants were removed by washing the solid in THF (three times) and $\mathrm{CH}_{2} \mathrm{Cl}_{2}$ (three times). Drying at room temperature under vacuum yielded a yellow powder of azide-functionalized UiO-66 (UiO-66- $\left.\mathrm{N}_{3}\right)$.

Synthesis of pyridyltriazol-functionalized UiO-66 (UiO-66-Pyta)

To a glass vial, azide-functionalized MOF (90 mg, $0.0471 \mathrm{mmol}, 0.283 \mathrm{mmol}$ of $-\mathrm{N}_{3}$ ) was suspended in degassed DMF (1.5 mL). 2-ethynylpyridine (1.4 equiv. in total vs. $\mathrm{N}_{3}$ loading, $0.396 \mathrm{mmol}$ ) was added and the resultant mixture stirred for 10 min followed by adding $\mathrm{Et}_{3} \mathrm{~N}$ (5 equiv., $1.415 \mathrm{mmol}, 0.2 \mathrm{~mL})$ and $\mathrm{CuI}(10 \mathrm{~mol} \%)$. The reaction mixture was stirred at $55^{\circ} \mathrm{C}$ for 48 h. The functionalized MOF was collected by filtration, washed by DMF (two times), and soaked at $55{ }^{\circ} \mathrm{C}$ in fresh DMF for $2 \mathrm{~h}$. The solid was then centrifuged and washed with $\mathrm{CH}_{3} \mathrm{CN}$ 
(three times) followed by soaking in $\mathrm{CH}_{3} \mathrm{CN}$ for $24 \mathrm{~h}$. The resultant MOF was then recovered and washed by THF (three times) and dried at room temperature under vacuum.

\subsection{Adsorption Experiments}

In this study, SPE experiments were carried out at ambient temperature. The $25 \mathrm{~mL}$ sample solution containing $1 \mathrm{mg} \mathrm{L}^{-1}$ of palladium was mixed homogeneously with $0.01 \mathrm{~g}$ adsorbent in a conical-shaped bottom glass tube. Later, the $\mathrm{pH}$ of this mixture was adjusted between 1 to 6 with $0.1 \mathrm{M} \mathrm{HNO}_{3}$ and $\mathrm{NaOH}$. After that, the mixture was shaken for enough time (2-30 min). After the extraction, the suspension was centrifuged at $5000 \mathrm{rpm}$. The supernatant solution was then discarded and the palladium ion amounts were determined in it by UV-Vis spectrophotometry. Also, for desorption measurements, the adsorbent was gathered in the bottom

of glass tube. For desorption of palladium from sorbent, the eluent solvent $\left(0.1 \mathrm{~mol} \mathrm{~L}^{-1} \mathrm{HNO}_{3}\right)$ was added to the adsorbent and the suspension was shaken for sufficient time (2-30 $\mathrm{min})$. Finally, the collected eluent solvent was discarded and 20\% KI solutions were added to it. This solution was transferred to a UV-Vis spectrophotometer for determination of amount of palladium.

The amount of palladium ions extracted from solution per unit mass of sorbent was obtained based on the following equation:

$q=\left[\frac{C_{i}-C_{f}}{M}\right] \times V$

Where $C_{i}$ and $C_{f}$ are the concentrations of palladium ion before and after extraction, $M$ is the mass of adsorbent (g) and $\mathrm{V}$ is the volume of the aqueous phase in $\mathrm{mL}$.

\subsection{Computational details}


The geometries of ligands and complexes in different possible bonding modes were optimized at the B3LYP method ${ }^{48,49}$ using the Gaussian09 program package. ${ }^{50}$ The relativistic effective core potential (ECP) basis set of Lanl2dz was used for the Pd(II) ion, ${ }^{51,52}$ and the 631G were used for the other atoms.

\subsection{Reusability Experiment for Suzuki-Miyaura Cross-Coupling Reaction}

UiO-66-Pyta bearing Pd ions (UiO-66-Pyta-Pd) was washed with methanol and dried under vacuum at $110{ }^{\circ} \mathrm{C}$ for $3 \mathrm{~h}$ and then used as catalyst for Suzuki-Miyaura cross-coupling reaction as follows: A mixture of bromobenzene $(1 \mathrm{mmol})$, phenylboronic acid $(1.2 \mathrm{mmol})$, $\mathrm{K}_{2} \mathrm{CO}_{3}(2.0 \mathrm{mmol})$, EtOH $(6 \mathrm{~mL})$ and catalyst $(10 \mathrm{mg})$ were placed in a Schlenk tube and stirred in air, at $80^{\circ} \mathrm{C}$ for $2 \mathrm{~h}$. After completion of the reaction, the catalyst was separated and then the mixture was extracted three times with ethyl acetate. The product yield was determined by gas chromatography (GC) analysis. Purified product was characterized by ${ }^{1} \mathrm{H}$ NMR spectroscopy (see SI).

\section{Result and Discussion}

\subsection{Characterization of multifunctional Zr-MOF, UiO-66-Pyta}

Firstly, UiO-66- $\mathrm{NH}_{2}$ was synthesized using Corma method. ${ }^{47,53}{ }^{1} \mathrm{H}$ NMR spectrum of digested MOF in a DMSO- $d_{6} / \mathrm{HF}_{\text {aq }}$ mixture showed a partial formylation $(\sim 21 \%$ of $-\mathrm{NHCHO}$ group) of 2-aminobenzene -1,4-dicarboxylic acid $\left(\mathrm{H}_{2} \mathrm{BDC}-\mathrm{NH}_{2}\right)$ by DMF, as impurity, due to the synthetic conditions (see NMR data in ESI, Figures S1-S3). Therefore, the as-synthesized UiO-66- $\mathrm{NH}_{2}$ was deformylated by post-synthetic deprotection (PMD) in refluxing methanol, converting the formylamido groups to amino groups (Figure S3). UiO-66- $\mathrm{NH}_{2}$ with chemical 
formula $\mathrm{Zr}_{6} \mathrm{O}_{4}(\mathrm{OH})_{4}\left(\mathrm{NH}_{2} \mathrm{BDC}\right)_{6}\left(\mathrm{NH}_{2} \mathrm{BDC}=\right.$ 2-aminoterephthalate $)$ consists of 12-coordinate hexanuclear $\left[\mathrm{Zr}_{6}\left(\mu_{3}-\mathrm{O}\right)_{4}\left(\mu_{3}-\mathrm{OH}\right)_{4}\right]^{12+}$ nodes connected with each other by 12 carboxylate groups of the linkers to give super octahedral and super tetrahedral cages. ${ }^{54,55}$ Using deprotected UiO66- $\mathrm{NH}_{2}$, the azide-functionalized UiO-66 $\left(\mathrm{UiO}-66-\mathrm{N}_{3}\right)$ was prepared by post-synthetic modification (PSM) with tert-butyl nitrite followed by reaction with trimethylsilyl azide. Finally, the azide-alkyne[3+2]-cycloaddition (click) reaction of 2-ethynylpyridine with the UiO-66- $\mathrm{N}_{3}$ gave pyridyltriazol-functionlized UiO-66, UiO-66-Pyta (Scheme 1).
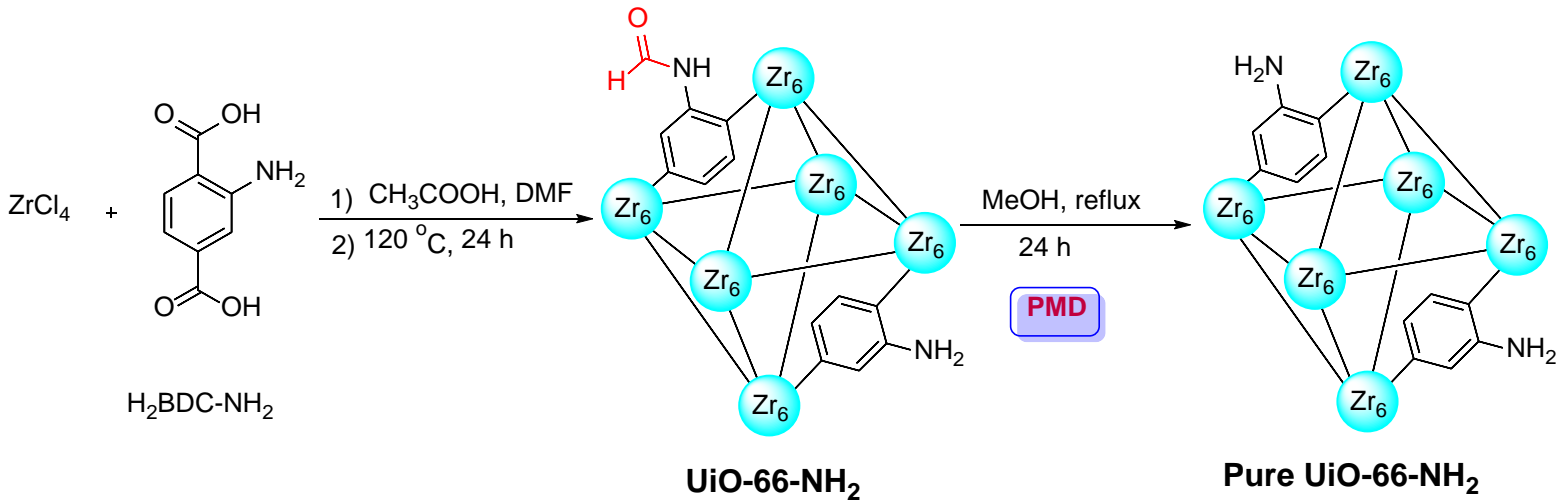

Pure UiO-66- $\mathrm{NH}_{2}$
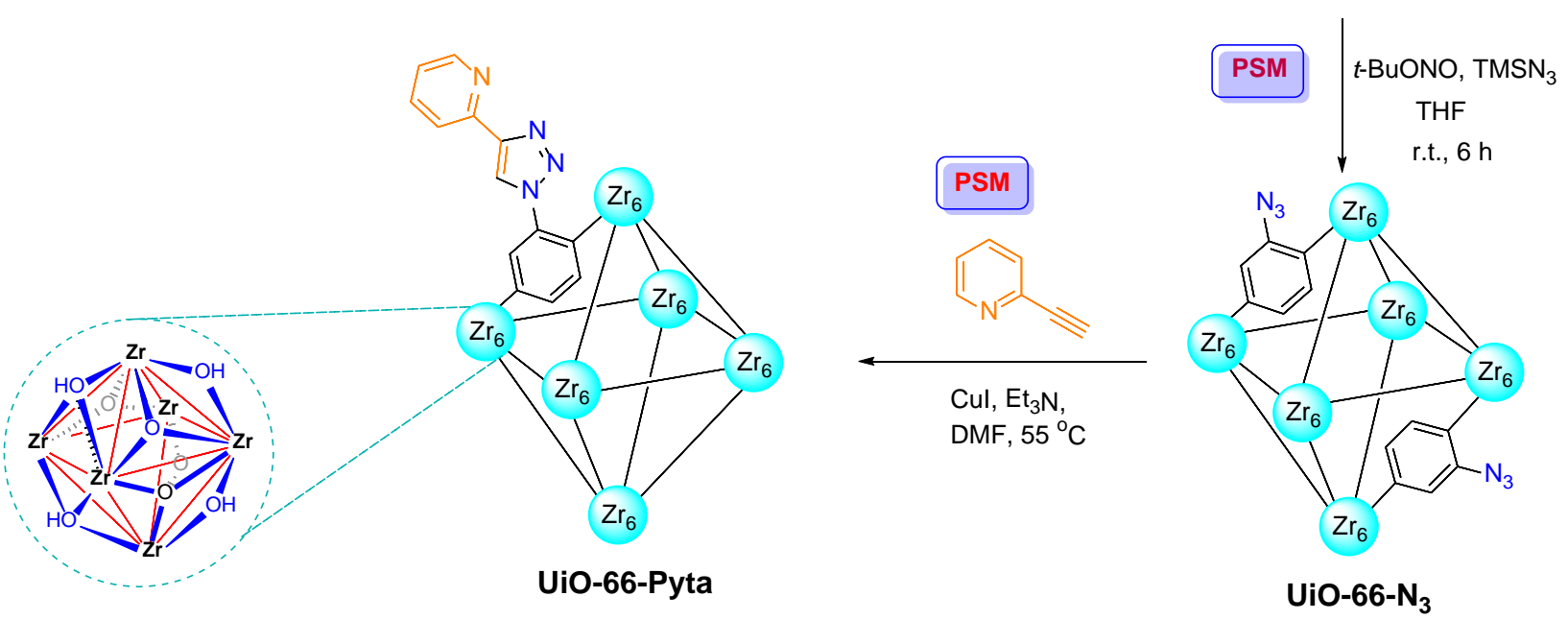

Scheme 1. Schematic synthesis; PMD, and PSMs of UiO-66- $\mathrm{NH}_{2}$ towards formation of UiO-66Pyta. 
${ }^{1} \mathrm{H}$ NMR spectra of the digested MOFs in HF/DMSO- $d_{6}$ solution indicate grafting of 95\% of azide groups for UiO-66- $\mathrm{N}_{3}$ and 24\% of Pyta ligand for UiO-66-Pyta (see Figs S4 \& S5 in ESI). FT-IR spectrum of the pure UiO-66- $\mathrm{NH}_{2}$ showed the disappearance of the peak at about $1650 \mathrm{~cm}^{-1}$ related to the formyl group after the deformylation process (Fig. 1). The FT-IR spectrum of UiO-66- $\mathrm{N}_{3}$ displayed the appearance of azide band at about $2125 \mathrm{~cm}^{-1}$. A significant decrease of the azide characteristic band (Fig. 1) after the click reaction was observed, in agreement with Pyta formation and synthesis of UiO-66-Pyta. FT-IR spectra are, thus, in accordance with the NMR data. 


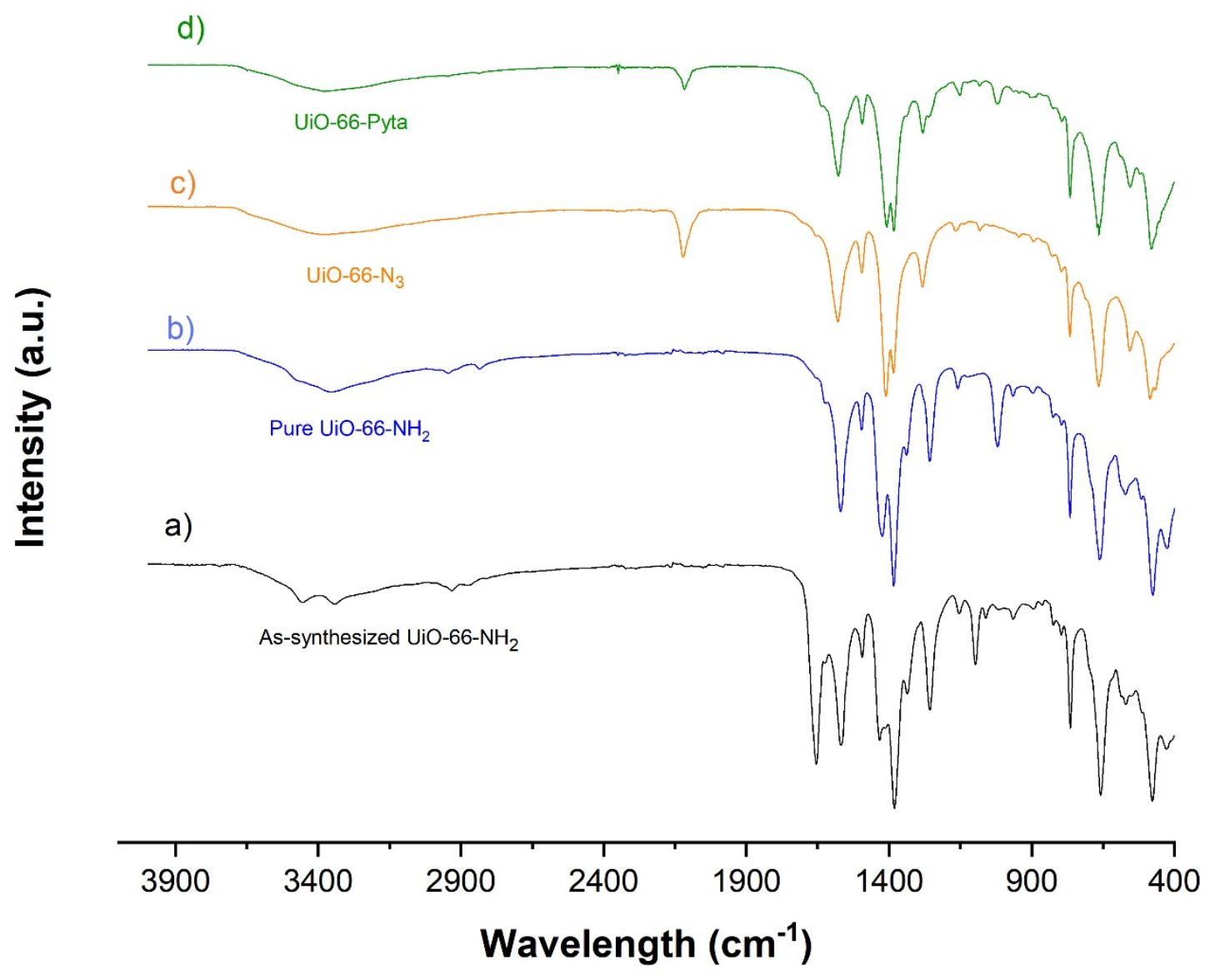

Figure 1. FT-IR spectra of UiO-66- $\mathrm{NH}_{2}$ and other corresponding $\mathrm{Zr}-\mathrm{MOF}$ obtained through the PMD and PSMs. From bottom to up: a) as-synthesized UiO-66- $\mathrm{NH}_{2}$, b) Pure UiO-66-NH2, c) UiO-66- $\mathrm{N}_{3}$, and d) UiO-66-Pyta

The phase purity of the MOFs submitted to three PSMs was characterized by PXRD. The peaks in the PXRD patterns of the MOFs match well with the simulated pattern of UiO-66 (Fig. 2). ${ }^{55}$ The PXRD patterns indicated that the UiO-66-Pyta is isostructural with the parent UiO-66. Also, the patterns showed that the crystallinity and structure of MOFs were retained during the modification process (PMD and PSMs) (Fig. 2). 


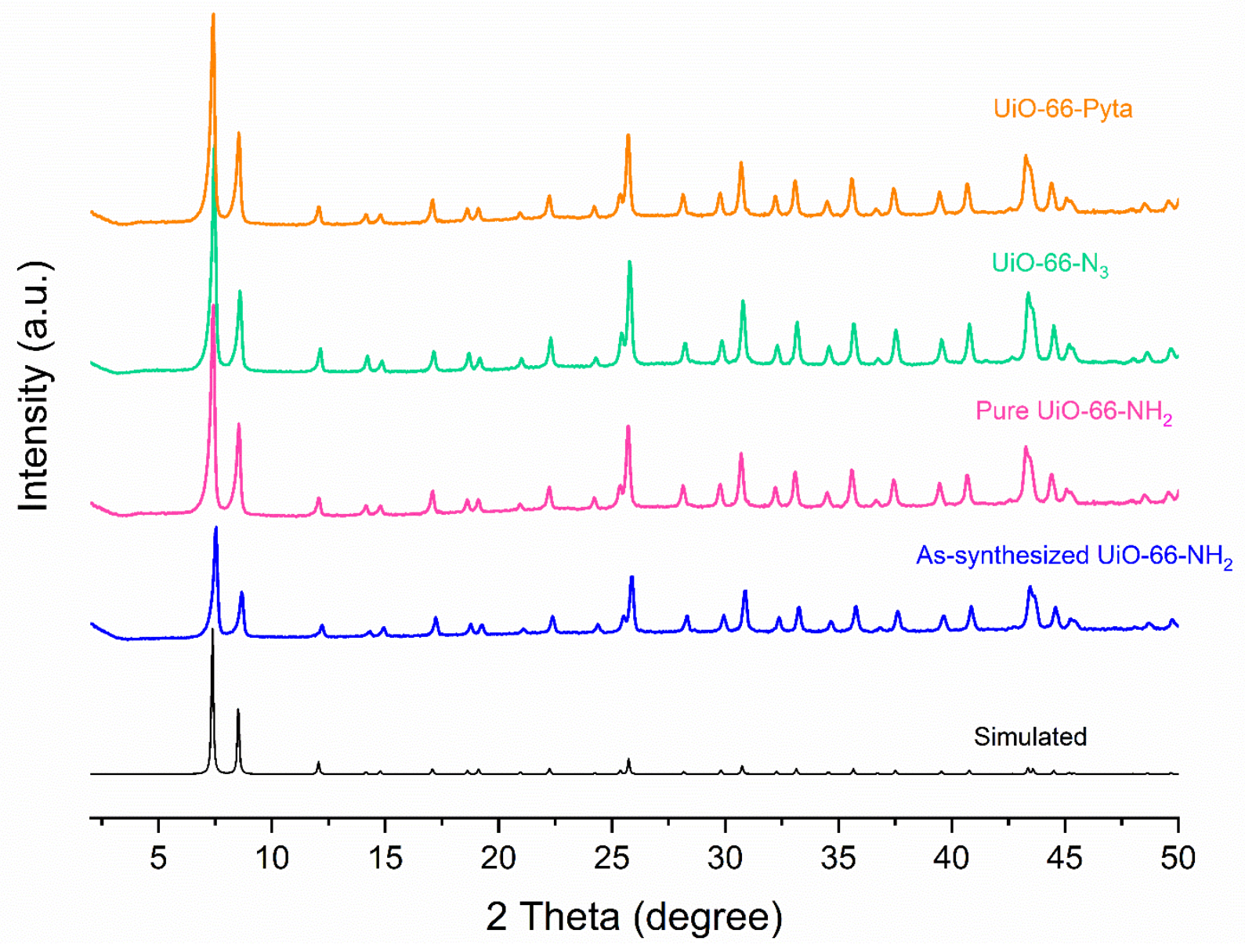

Figure 2. PXRD patterns of simulated UiO-66(Zr) and synthesized Zr-MOFs through the modification processes: as-synthesized UiO-66- $\mathrm{NH}_{2}$, pure $\mathrm{UiO}-\mathrm{NH}_{2}$, UiO-66- $\mathrm{N}_{3}$, and UiO-66Pyta.

Nitrogen gas sorption measurement of the activated UiO-66-Pyta at $77 \mathrm{~K}$ exhibited type I gas adsorption isotherm (Fig. 3) with a Brunauer-Emmett-Teller (BET) surface area of $460 \mathrm{~m}^{2} \mathrm{~g}^{-}$ ${ }^{1}$. As seen in Fig. 3, the BET surface area of UiO-66- $\mathrm{NH}_{2}$ was increased from $890 \mathrm{~m}^{2} \mathrm{~g}^{-1}$ to 1120 $\mathrm{m}^{2} \mathrm{~g}^{-1}$ after the first PSM (deprotected UiO-66- $\mathrm{NH}_{2}$ ) which then decreased, respectively, to 785 
$\mathrm{m}^{2} \mathrm{~g}^{-1}$ through the second PSM (UiO-66- $\mathrm{N}_{3}$ ) and $460 \mathrm{~m}^{2} \mathrm{~g}^{-1}$ via the last PSM (UiO-66-Pyta). The results are in agreement with the success of the modification steps.

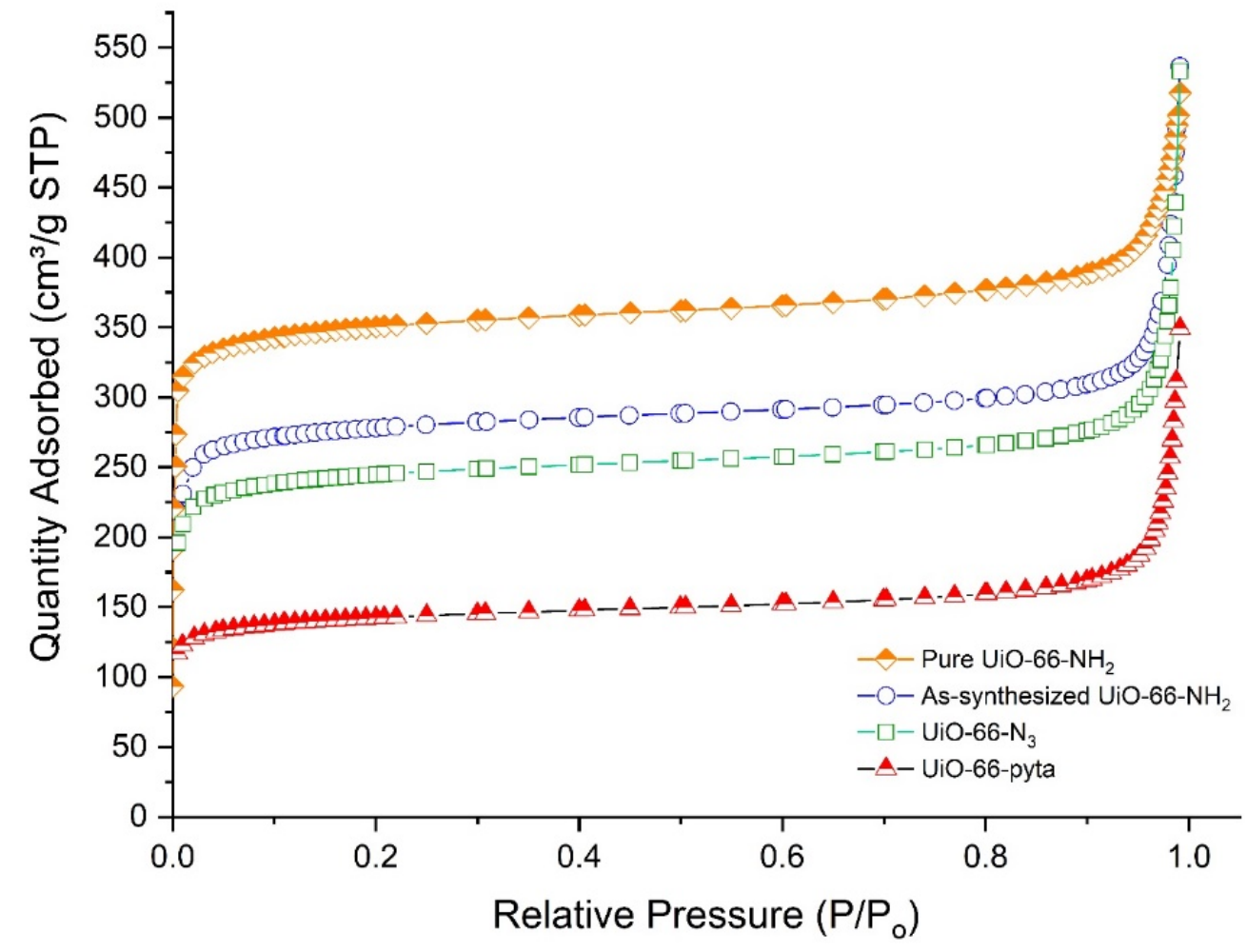

Figure 3. $\mathrm{N}_{2}$ sorption measurements at $77 \mathrm{~K}$ for as-synthesized $\mathrm{UiO}-66-\mathrm{NH}_{2}$, pure $\mathrm{UiO}-\mathrm{NH}_{2}$, UiO-66-N 3 , and UiO-66-Pyta.

The scanning electron microscope (SEM) images of the UiO-66-Pyta showed cubicshaped crystals with a mean diameter of about $100 \mathrm{~nm}$ (Figure 4). It was observed that the UiO66- $\mathrm{NH}_{2}$ crystals retained their size after the three consecutive PSMs. 

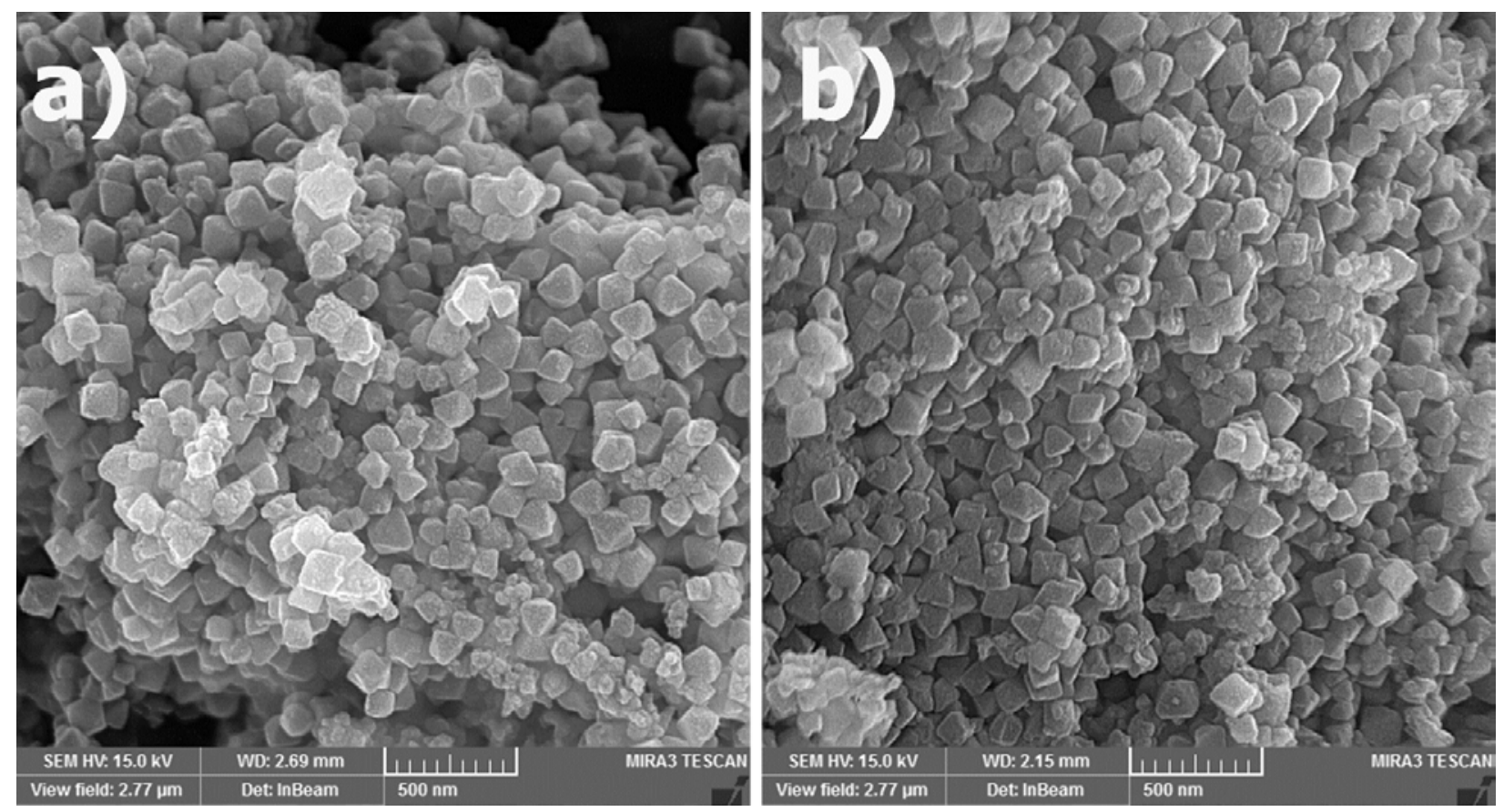

Figure 4. SEM images of a) as-synthesized UiO-66- $\mathrm{NH}_{2}$ (before the post modifications) and b) UiO-66-Pyta (MOF obtained after the post modifications).

Furthermore, thermogravimetric analysis (TGA) of the solid under $\mathrm{N}_{2}$ atmosphere indicated that the MOF is stable up to $\sim 500{ }^{\circ} \mathrm{C}$ (Figure S6). It is supposed that the weight loss below $200{ }^{\circ} \mathrm{C}$ is due to the evaporation of the solvent trapped in the framework and mass lose above $370{ }^{\circ} \mathrm{C}$ (in the temperature range $370-550^{\circ} \mathrm{C}$ ) is related to the decomposition of the organic linker. Overall, the available characterization data confirmed the successful synthesis of the UiO-66-Pyta via the three PSMs.

\subsection{Optimization of the extraction conditions using the UiO-66-Pyta as adsorbent}

The $\mathrm{pH}$ has an important role controlling palladium ion extraction. According to Fig. 5, the extraction efficiency (R\%) increases with an increase in $\mathrm{pH}$ of solution from 1 to 4.5 and after that $\mathrm{R} \%$ remains nearly constant with subsequent increases of $\mathrm{pH}$. Therefore, the maximum 
$\mathrm{R} \%$ of palladium ions is already reached at $\mathrm{pH} 4.5$. The $\mathrm{pH}$ effect on the extraction recovery may be related to the surface charge of adsorbent and palladium ions. Zeta potential of the adsorbent at various $\mathrm{pH}$ was shown in Figure S7. Based on the Fig. S7, the isoelectric point of the adsorbent is about 3.9. Therefore, the adsorbent has positive charge below of isoelectric point and negative charge above it. In $\mathrm{pH} 4.5$, the adsorbent has negative charge while palladium ions have positive charge, thereby, the condition for an optimal extraction is fulfilled. At $\mathrm{pH}$ values below 3.9, the electrostatic repulsions between adsorbent and analyte ions results in the decrease of the extraction efficiency. Thus, $\mathrm{pH} 4.5$ was used in the subsequent experiments.

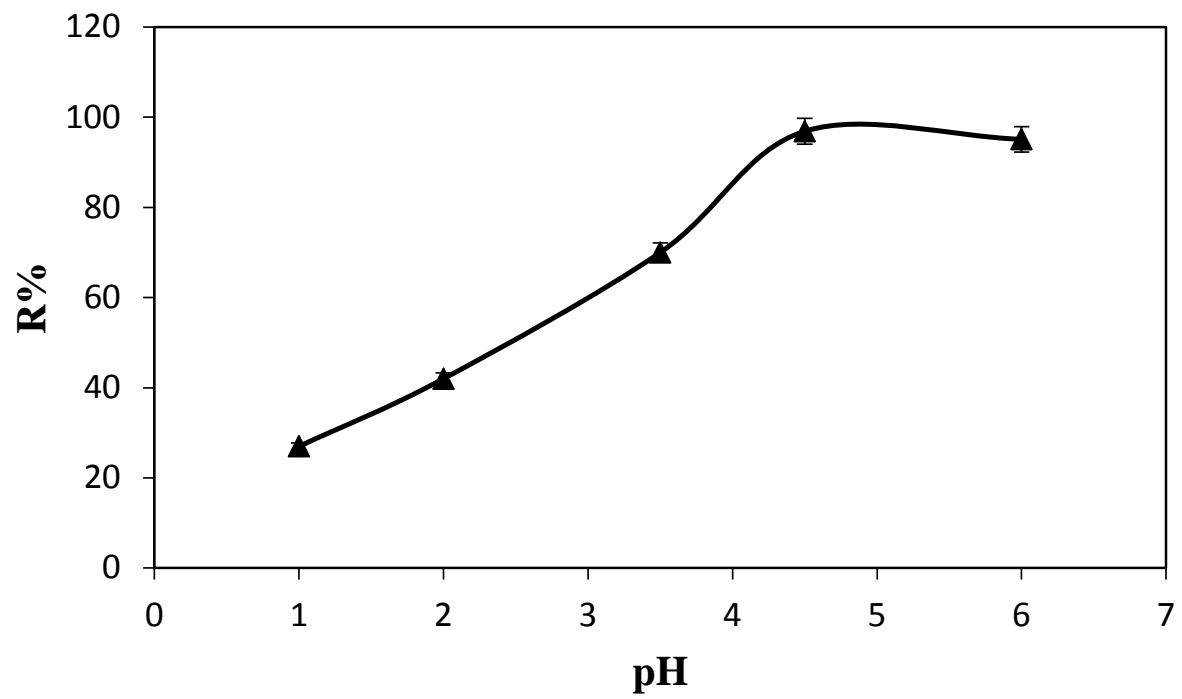

Figure 5. Effect of $\mathrm{pH}$ on the extraction efficiency of palladium ions (Extraction conditions: amount of adsorbent $=10 \mathrm{mg}$, and extraction time $=10 \mathrm{~min}$ ).

The effect of mass adsorbent on the extraction of palladium ions was also studied. As depicted in Figure S8, the data showed that the R\% increased with an increase of the amount of the adsorbent from $5 \mathrm{mg}$ to $10 \mathrm{mg}$, presenting the considerable strong extraction capability of the 
adsorbent. When the amount of adsorbent was higher than $10 \mathrm{mg}$, the extraction efficiency was not further increased. Thereby, in the next experiments, $10 \mathrm{mg}$ of the MOF sorbent was used. The effect of extraction time was then investigated in the range of 2 min to $20 \mathrm{~min}$. The results indicated that 5 min was enough to extract palladium ions from the aqueous solution (Figure 6). There was no significant increasing in the extraction efficiency of analyte with longer extraction times. These results indicated that an efficient extraction of palladium ions could be attained in 5 min. Therefore, this extraction time was used for subsequent experiments. The high efficiency and fast extraction time demonstrated the strong interaction between adsorbent and palladium ions under the suggested procedure. Furthermore, the effect of MOF particle size on the uptake of Pd was considered. When, the average particle size was decreased from $\sim 100 \mathrm{~nm}$ to $\sim 70 \mathrm{~nm}$ (preparation details in SI and Fig. S9), only a slight decrease of adsorption time (from 5 min to $\sim 4$ min) without no significant e on Pd(II) removal was observed.

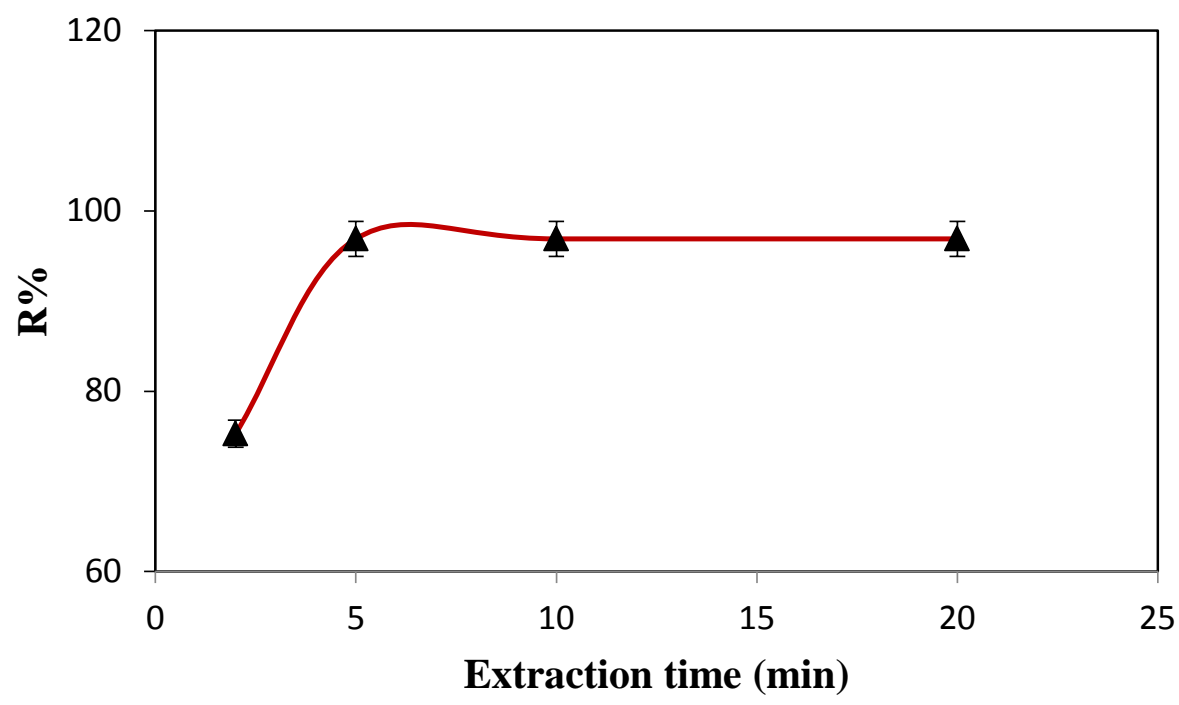

Figure 6. Effect of extraction time on the extraction efficiency of palladium ions (Extraction conditions: amount of adsorbent $=10 \mathrm{mg}$, and $\mathrm{pH}=4.5$ ). 
Desorption of palladium ions from the adsorbent is also crucial in SPE. Hence, a series of experiments on the eluent solvent, volume of eluent, and desorption time were performed. Nitric acid and hydrochloric acid were evaluated as eluent solvent using $10 \mathrm{mg}$ of the adsorbent. The results showed that desorption efficiency of $\mathrm{HNO}_{3}$ was better than that of $\mathrm{HCl}$. Thus, $\mathrm{HNO}_{3}$ was used as optimal eluent solvent. After that, we investigated the concentration and volume effect of $\mathrm{HNO}_{3}$ on the extraction efficiency. According to Fig. S10, with the increase of concentration of the eluent solvent, the extraction efficiency was increased. Also, the volumes of 0.5, 0.7 and 1.0 $\mathrm{mL}$ were examined and the results showed the extraction efficiency was remained almost constant. Based on these experiments, $1.0 \mathrm{~mL}\left(0.1 \mathrm{~mol} \mathrm{~L}^{-1}\right)$ of $\mathrm{HNO}_{3}$ for 5 min was chosen for desorption experiments. Sample volume in preconcentration method is an important parameter, there being convenient issue to achieve the highest possible preconcentration factor, particularly when analyzing trace elements in real samples. Therefore, the sample volume effect was studied in the range of 25 to $500 \mathrm{~mL}$ under optimal conditions. In this research, quantitative extraction efficiency was considered when the extracted Pd overcomes 95\% of the initial value. The extraction efficiency of palladium ions was quantitative to $250 \mathrm{~mL}$; beyond this volume the extraction efficiency decreased. Thereby, the $250 \mathrm{~mL}$ was taken as an optimal sample volume. The reason for the decrease in palladium extraction efficiency could be the saturation of the active sites of the sorbent by solvent competition. Thus, it was concluded that the preconcentration factor was 250.0 with the eluent volume of $1.0 \mathrm{~mL}$.

\subsection{Adsorption performance}

Figure 7 indicated the adsorption isotherm which was fitted to the Langmuir model by nonlinear regression model. The equation of this model is given as follows. ${ }^{56,57}$ 
$\frac{\mathrm{C}_{\mathrm{e}}}{\mathrm{q}}=\frac{1}{\mathrm{Kq}_{\mathrm{m}}}+\frac{\mathrm{C}_{\mathrm{e}}}{\mathrm{q}_{\mathrm{m}}}$

Where $\mathrm{q}\left(\mathrm{mg} \mathrm{g}^{-1}\right)$ is the equilibrium adsorption amount of palladium ions on the adsorbent and Ce $\left(\mathrm{mg} \mathrm{mL}^{-1}\right)$ is the equilibrium concentration of palladium ions in the sample solution. Furthermore, $\mathrm{q}_{\mathrm{m}}\left(\mathrm{mg} \mathrm{g}^{-1}\right)$ is the maximum adsorption amount of palladium ions and $\mathrm{K}\left(\mathrm{mL} \mathrm{mg}^{-1}\right)$ is the Langmuir adsorption constant. According to the results obtained by the model, the $\mathrm{q}_{\mathrm{m}}$ of the adsorbent was found to be $294.1 \mathrm{mg} \mathrm{g}^{-1}$ with determination coefficient $\left(\mathrm{R}^{2}\right)$ of 0.98 .

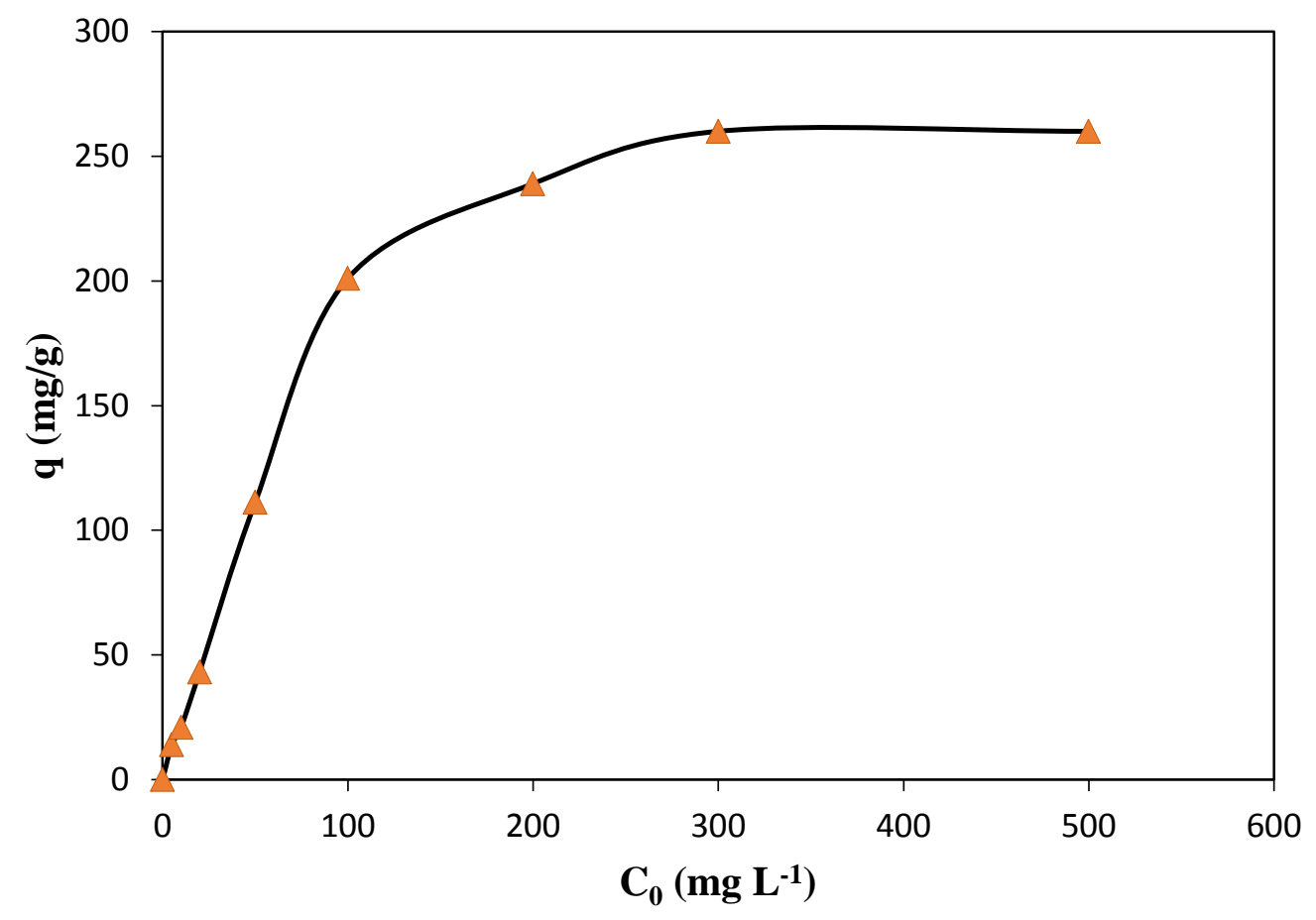

Figure 7. Palladium ions adsorption equilibrium isotherms (Extraction conditions: amount of adsorbent $=10 \mathrm{mg}, \mathrm{pH}=4.5$, and extraction time $=5 \mathrm{~min})$.

\subsection{Interference ions}


Ion selectivity is an important factor for selective extraction and detection of palladium ions in aqueous samples. Also, numerous cations may be present in natural water samples with palladium ions. In this study, we investigated the selectivity of the adsorbent in the presence of several foreign ions, which can coexist with palladium ions in natural water samples. Table S1 shows the tolerance limits of each ion. These results showed that the UiO-66-Pyta adsorbent was capable of selective palladium ions even in the presence of the high concentration of interfering ions, including $\mathrm{Li}^{+}, \mathrm{Na}^{+}, \mathrm{K}^{+}, \mathrm{Ca}^{2+}, \mathrm{Mg}^{2+}, \mathrm{Zn}^{2+}, \mathrm{Pb}^{2+}, \mathrm{Fe}^{3+}, \mathrm{Mn}^{2+}, \mathrm{Ni}^{2+}, \mathrm{Co}^{2+}, \mathrm{Al}^{3+}, \mathrm{Cu}^{2+}, \mathrm{Ag}^{+}$.

\subsection{Effect of salt addition}

In the present study, the effect of salt addition on the extraction of Pd by the sorbent was investigated as shown in Fig. S11. According to this Figure, the extraction recovery decreased when the concentration of salt increased due to the increasing competitive ions for the active adsorption sites.

\subsection{Comparison of this method with the other works}

Table 1 shows a comparison of the extraction efficiency of above UiO-66-Pyta adsorbent with previously reported sorbent for palladium ions. According to these results, UiO-66-Pyta adsorbent has the maximum adsorption capacity so far reported and the material can be used as efficient and appropriate adsorbent for the extraction of palladium ions from aqueous solutions. Interestingly, the functionalized MOF showed higher maximum adsorption capacity than UiO-66 and $\mathrm{UiO}-66-\mathrm{NH}_{2}$ under identical conditions.

Table 1. Comparison of this method with other related 
procedures for determination of palladium ions

\begin{tabular}{|c|c|c|}
\hline Adsorbent & $\mathrm{q}_{\mathrm{m}}\left(\mathrm{mg} \mathrm{g}^{-1}\right)$ & Ref \\
\hline $\begin{array}{l}\text { Ethylenediamine-modified magnetic chitosan } \\
\text { nanoparticles }\end{array}$ & 138.0 & [11] \\
\hline Chitosan/graphene oxide composite & 216.92 & [12] \\
\hline Graphene oxide & 80.77 & [13] \\
\hline Functionalized mesoporous silica & 184.5 & [14] \\
\hline Aliquat-336 impregnated onto SBA-15 & 212.76 & [15] \\
\hline UiO-66 & 125.0 & $\begin{array}{l}\text { This } \\
\text { method }\end{array}$ \\
\hline $\mathrm{UiO}-66-\mathrm{NH}_{2}$ & 197.0 & $\begin{array}{l}\text { This } \\
\text { method }\end{array}$ \\
\hline UiO-66-Pyta & 294.1 & $\begin{array}{l}\text { This } \\
\text { method }\end{array}$ \\
\hline
\end{tabular}

\subsection{Reusability of the adsorbent for extraction of palladium ions}

Figure 8 shows the reusability of adsorbent for removal of palladium ions. According to this figure, the extraction efficiency was reduced from $96.9 \%$ to $81.7 \%$ after 5 times. The decrease could be ascribed to the strong binding of some Pd(II) ions to the functional groups of the nominal MOF, leading to an incomplete desorption of Pd(II) species, and thereby, a slightly decrease on the number of binding sites for the consecutive sorption/desorption cycle. ${ }^{58}$ 
Nevertheless, in the fifth cycle, the extraction efficiency was still as high of $81.7 \%$. These measurements revealed that UiO-66-Pyta has the potential to be used as a recyclable sorbent for extraction of Pd(II) ions from aqueous solution.

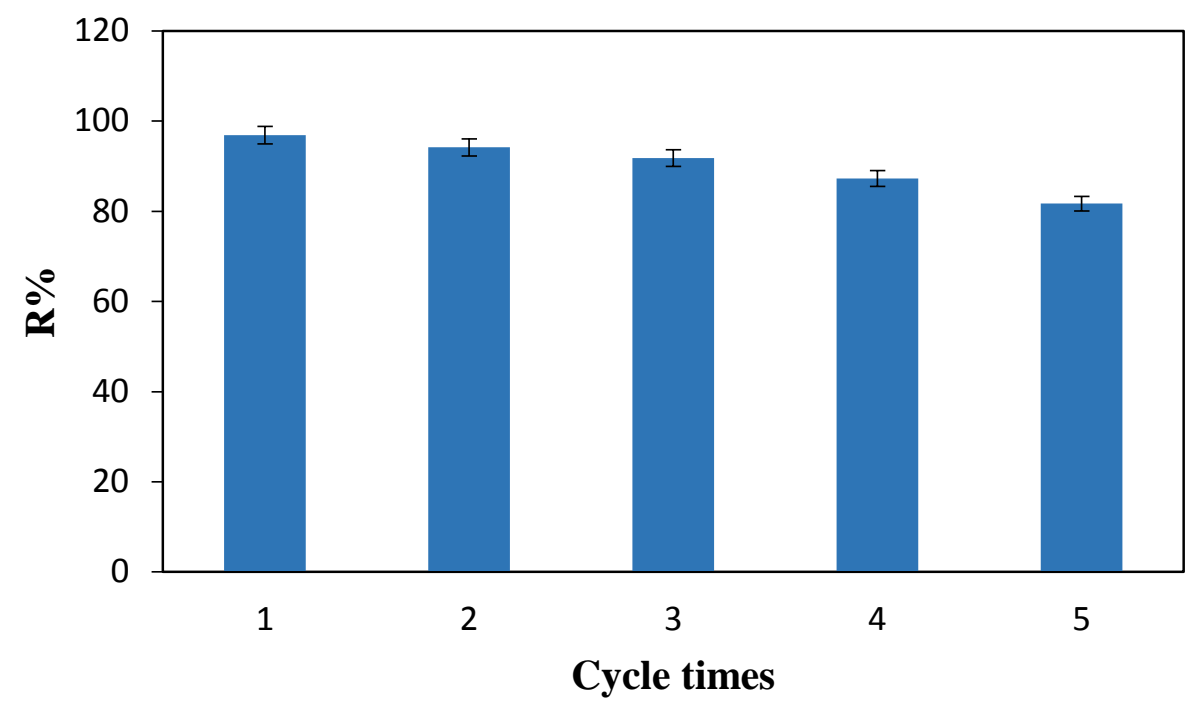

Figure 8. Reusability cycles of adsorbent for extraction of Pd ions.

\subsection{Procedure validation}

Under optimized conditions, the UiO-66-Pyta sorbent was used to determine the figure of merits such as, linearity, limit of detection (LOD), and intra- and inter-day precisions. The proposed method provided the linearity in the range of 0.01 to $1.5 \mathrm{mg} \mathrm{L}^{-1}$ with the correlation coefficient $\left(\mathrm{R}^{2}\right)$ of 0.999 . The $\mathrm{LOD}=3(\mathrm{Sd})$ blank/ $\mathrm{m}$ (Sd is the standard deviation and $\mathrm{m}$ is the calibration curve slope) of $1.9 \mu \mathrm{gL}^{-1}$ was obtained. The precision was characterized with the intra-day and inter-day relative standard deviation $\left(\mathrm{RSD} \%, \mathrm{n}=5, \mathrm{c}=0.1 \mathrm{mg} \mathrm{L}^{-1}\right)$ on the same day and five consecutive days. The intra-day and inter-day precisions were obtained 3.6\% and 
1.7\%, respectively. These results illustrated the appropriate and satisfactory reputability and reproducibility of the procedure for extraction of palladium ions in aqueous samples.

\subsection{Adsorption Mechanism}

For the study of the Pd adsorption mechanism by UiO-66-Pyta, zeta potential measurement of the sorbent was firstly carried out at different $\mathrm{pH}$ (Figure S7). As shown in the Fig. S7, the isoelectric point of adsorbent is about 3.9, indicating that the sorbent is negatively charged at the $\mathrm{pH}$ above 3.9. This is useful for the sorption of Pd(II) as a soft acid. Therefore, in $\mathrm{pH}$ 4.5, $\mathrm{Pd}(\mathrm{II})$ can coordinate to the nitrogen donor atoms of the ligand, corresponding to the optimal extraction conditions. The interaction between Pd(II) and UiO-66-Pyta was investigated using FT-IR, PXRD, SEM/EDX, TGA, and XPS. In contrast to the spectrum of UiO-66-Pyta, the FTIR spectrum of palladium-loaded UiO-66-Pyta exhibited a shift of the peaks at 3442, 1581 (C=N band), 1386, 1259 (C-N band) and $1151 \mathrm{~cm}^{-1}$ to 3413, 1575, 1383, 1257, and $1151 \mathrm{~cm}^{-1}$, respectively (Fig. S12). These shifts indicated that Pyta and $\mathrm{Zr}-\mathrm{oxo} / \mathrm{OH}^{8}$ might be the active sites in the sorption of $\mathrm{Pd}(\mathrm{II}) .{ }^{45,}{ }^{59}$ On the other hand, the comparison of the FT-IR spectrum of the MOF before and after Pd loading also indicates that the structure of the MOF was retained after palladium adsorption. The UiO-66-Pyta-Pd was then characterized using PXRD to investigate whether palladium ions are certainly present in the MOF or not. As given in Fig. S13, the XRD patterns of UiO-66-Pyta before and after Pd loading are almost the same with the exception of the peak at about $39.9^{\circ}$ related to the (111) plane of palladium (JCPDS \# 89-4897), ${ }^{60}$ probably indicating the presence of Pd species. Furthermore, SEM and energy-dispersive spectroscopy (EDS) were performed for UiO-66-Pyta before and after extraction of $\mathrm{Pd}(\mathrm{II})$ and the results are given in Figure S14 \& S15. No difference in morphology was observed between the two set of 
images (Figs 4 and S14). The EDS analysis of UiO-66-Pyta-Pd revealed the presence of elements such as $\mathrm{C}, \mathrm{O}, \mathrm{Zr}$ and $\mathrm{Pd}$, confirming the Pd adsorption on the UiO-66-Pyta (Figure S15). Furthermore, TGA curve of the UiO-66-Pyta-Pd is almost coincident to that of the pristine MOF, UiO-66-Pyta, revealing that the structure integrity is maintained throughout the Pd adsorption process (Figure S6). These results indicated the stability of UiO-66-Pyta during the adsorption-desorption experiments. In comparison to UiO-66-Pyta, an additional experiment was performed using the pristine $\mathrm{Zr}-\mathrm{MOF}$ (UiO-66- $\mathrm{NH}_{2}$ ) as sorbent under the optimized extraction conditions. Inductively coupled plasma atomic emission spectroscopy (ICP-AES) analysis of UiO-66-Pyta-Pd showed 2.3-fold higher palladium loading than UiO-66- $\mathrm{NH}_{2}-\mathrm{Pd}$. The $\mathrm{q}_{\mathrm{m}}$ of the UiO-66- $\mathrm{NH}_{2}$ as adsorbent was found to be $197 \mathrm{mg} \mathrm{g}^{-1}$ which is less than that of the UiO-66-Pyta (see Table 1). The experiments confirmed the effective role of the Pyta as bidentate ligand ${ }^{45}$ and active binding site for Pd(II) sorption.

To further characterize the nature of the binding sites, X-ray photoelectron spectroscopy (XPS) profiles of UiO-66-Pyta before and after Pd(II) adsorption were recorded. XPS analysis of the UiO-66-Pyta-Pd exhibited two peaks attributed to the Pd(II) at binding energy at 334-346 $\mathrm{eV},{ }^{61}$ confirming the presence of Pd(II) into the UiO-66-Pyta (Figures S16). The comparison of the $\mathrm{N}$ 1s and $\mathrm{O}$ 1s binding energies for UiO-66-Pyta before and after Pd(II) adsorption is shown in Figure S17. The N 1s spectrum of the UiO-66-Pyta-Pd showed a shift in the peak position towards higher binding energy $(\sim 1 \mathrm{eV})$ compared with the as-prepared UiO-66-Pyta, indicating a decrease in the electron density of $\mathrm{N}$ atoms caused by the strong coordination of $\mathrm{N}$ with $\mathrm{Pd}^{2+}$. These observations are in good agreement with those reported in the literature on the coordination of $\mathrm{Pd}^{2+}$ ions on $\mathrm{N}$ atoms. ${ }^{44,62,63}$ The $\mathrm{N}$ 1s spectrum can be deconvoluted in three main components: $\mathrm{C}=\mathrm{N}(399.39 \mathrm{eV})$ and $\mathrm{N}-\mathrm{N}=\mathrm{N}(400.7$ and $401.7 \mathrm{eV})$ of the pyridyltriazol, and 
the $-\mathrm{N}=\mathrm{N}^{+}=\mathrm{N}^{-}$(400.9 and $402 \mathrm{eV}$ ) of the azido groups. ${ }^{63,64}$ The O 1s spectral signal (Figure S17) of the UiO-66-Pyta-Pd also displays a contribution of oxygen coordinated to Pd ions, as it is evident from its relatively peak broadness compared to that of UiO-66-Pyta, in agreement with the reported data for Zr MOF adsorbents towards metal binding. ${ }^{65-69} \mathrm{O}$ 1s spectrum peak before $\mathrm{Pd}(\mathrm{II})$ adsorption corresponds to oxygen atoms present as the $\mathrm{Zr}-\mathrm{oxo} / \mathrm{OH}$ on $\mathrm{Zr}_{6}$ nodes and to the dicarboxylate linkers. ${ }^{20,65,66}$ XPS data indicate that $\mathrm{Pd}^{2+}$ interact not only $\mathrm{N}$ atoms, but also with oxygen functional groups, also in good agreement with previous reports. ${ }^{65-69}$ It should be, however, noted that $\mathrm{Pd}(\mathrm{II})$ is a soft metal ion and has a high affinity for soft donor atoms. ${ }^{70}$ Therefore, Pd forms stronger bonds with nitrogen compared to oxygen. Hence, the O 1s, N 1s, and Pd 3d XPS spectra data confirm that $\mathrm{Pd}^{2+}$ is adsorbed by the UiO-66-Pyta, nitrogencontaining functional groups playing a major role as binging sites.

To gain further understanding on the interaction of Pd(II) within UiO-66-Pyta, DFT calculations were performed to assess the potential binding sites of UiO-66-Pyta for palladium adsorption and their relative interaction energy. Accordingly, the optimized geometries (Figure 9) and the binding energies (Table 2) for a series of Pd(II) complexes taken as models of the different binding site in UiO-66-Ptya were calculated. As shown in Figure 9, the adsorption of Pd(II) was studied for a series of structures modelling the following binding sites of UiO-66Pyta: (I) N3 and N4 sites of Pyta ligand, (II) N2 of Pyta ligand, (III) N3 of the residual azide groups, (IV) $\mathrm{N} 1$ of the residual azide groups, $(\mathbf{V})$ oxygen groups of $\mathrm{Zr}_{6}$-node $\left(\mu_{3}-\mathrm{OH}\right)$, and $(\mathbf{V I})$ cation- $\pi$ interaction with phenyl ring. 


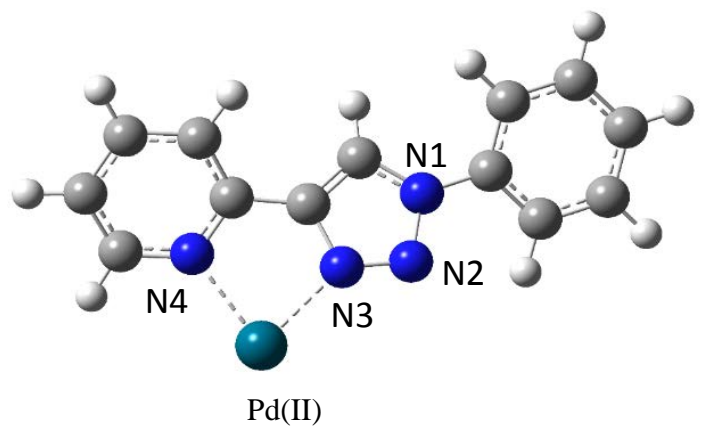

(III)

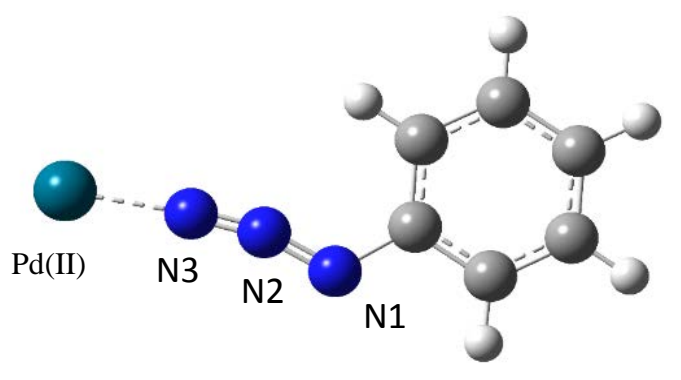

(V)

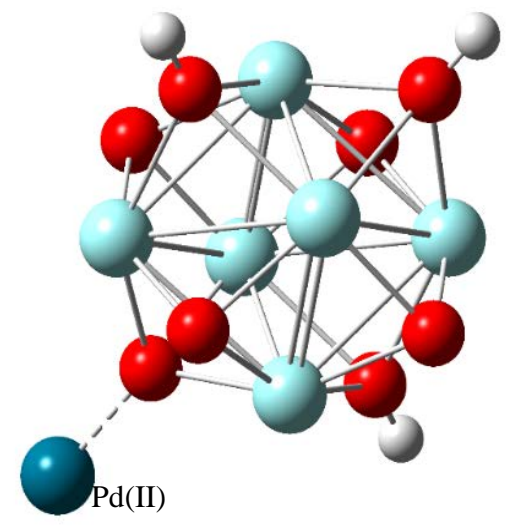

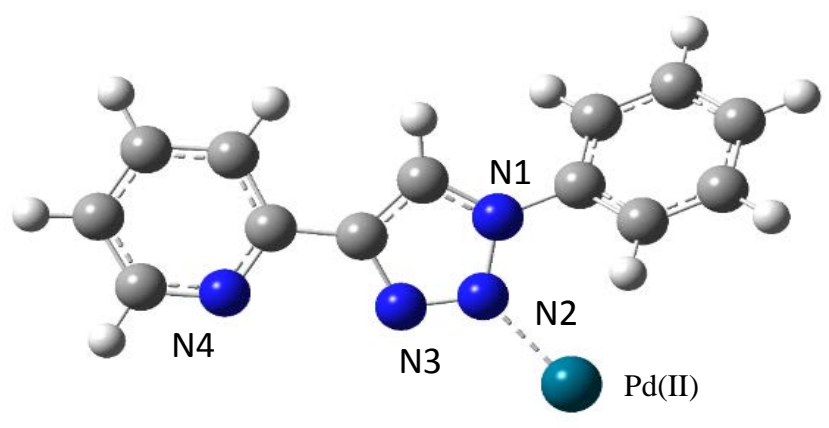

(IV)

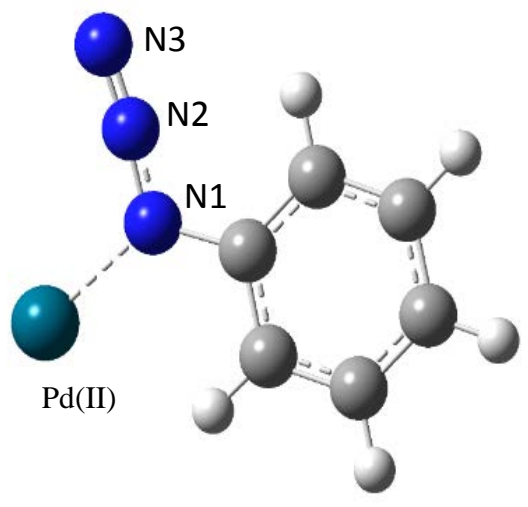

(VI)

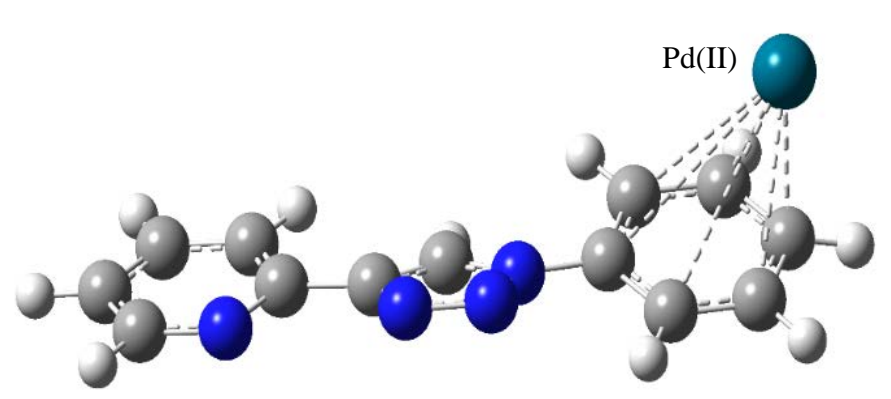

Figure 9. Optimized structures of different single ligand binding sites of UiO-66-Pyta for the adsorption of Pd(II): (I) N3 and N4 sites of Pyta ligand, (II) N2 of Pyta ligand, (III) N3 of the residual azide groups, (IV) $\mathrm{N} 1$ of the residual azide groups, (V) oxygen groups of $\mathrm{Zr}_{6}$-node $\left(\mu_{3^{-}}\right.$ 
$\mathrm{OH}$ ), and (VI) cation- $\pi$ interaction with phenyl ring. The dark grey, white, dark blue, red, and light blue spheres are carbon, hydrogen, nitrogen, oxygen, and zirconium atoms.

The binding energy was calculated as the difference between the energy of the complex and the sum of the energies of its fragments (ligand and Pd(II)):

$$
\Delta \mathrm{E}=\mathrm{E}_{\text {complex }}-\left(\mathrm{E}_{\text {ligand }}+\mathrm{E}_{\mathrm{Pd}(\mathrm{II})}\right)
$$

where $\mathrm{E}$ is the electronic energy of each optimized structure.

The $\Delta \mathrm{E}$ values (in $\mathrm{kcal} \mathrm{mol}^{-1}$ ) for the adsorption of Pd(II) by the mentioned binding sites are summarized in Table 2.

Table 2. The results of the calculations at the B3LYP/(C, H, O, N: 6-31g; Pd(II): LANL2DZ) level of theory.

\begin{tabular}{cc}
\hline Optimized structure & $\Delta \mathrm{E}\left(\mathrm{kcal} \mathrm{mol}^{-1}\right)$ \\
\hline I & -76.53 \\
II & -38.94 \\
III & -26.51 \\
IV & -25.50 \\
V & -46.69 \\
VI & -22.08 \\
\hline
\end{tabular}

As can be seen in Table 2, the adsorption strength follows the order of $\mathbf{I}(-76.53)<\mathbf{V}$ (46.69) < II (-38.94) < III (-26.51) < IV (-25.50) < VI (-22.08). According to the calculations, it appears that all the binding sites could have interaction with $\operatorname{Pd}(\mathrm{II})$ in water medium. Remarkably, the results proved that the chelation of Pd(II) ion simultaneously with two $N$ atoms in Pyta as bidentate ligand (structure I) is the most stable and favorable one among the other interactions considered. Moreover, interaction of $\mathrm{Pd}(\mathrm{II})$ with the aromatic ring (structure VI) of 
the linker through the cation $\cdots \pi$ interactions has a similar adsorption energy as that of $\operatorname{Pd}($ II) interaction with the azide $\mathrm{N}$ atoms. All the above observations confirmed that the plausible selective adsorption mechanism was due to the interactions between palladium(II) and the $N$ binding sites of Pyta, but Pd(II) can interact also with other possible sites.

\subsection{Sample analysis}

The possibility that the UiO-66-Pyta adsorbent based SPE coupled with UV-Vis spectrophotometric procedure for the determination of palladium in real samples was also examined and the results presented in Table 3. The real samples were collected from Zabol city in Iran. The results showed that UiO-66-Pyta has good accuracy for extraction of palladium ions from real samples. Therefore, this procedure could be applied successfully for both extraction and determination of palladium ions from natural water samples.

Table 3. Determination of palladium ions in water samples.

\begin{tabular}{lccc}
\hline \multirow{2}{*}{ Sample } & \multicolumn{2}{c}{ palladium content $\left(\mu \mathrm{g} \mathrm{L}^{-1}\right)$} & $\mathrm{R} \%$ \\
\cline { 2 - 3 } & Added & Found $\left( \pm{ }^{\mathrm{a}} \mathrm{RSD} \%\right)$ & - \\
\hline Tap water & 50.0 & - & 99.0 \\
& 100.0 & $49.5( \pm 1.7)$ & 98.5 \\
Ground water & - & - & - \\
& 50.0 & $49.3( \pm 1.6)$ & 98.6 \\
& 100.0 & $97.9( \pm 1.5)$ & 97.9 \\
\hline${ }^{a}$ Relative standard deviation & & &
\end{tabular}




\subsection{Reuse of the UiO-66-Pyta-Pd as catalyst}

As a case study, the UiO-66-Pyta adsorbed Pd ions was used as a catalyst for SuzukiMiyaura cross-coupling reaction ${ }^{45}$ (see Scheme S1). Notably, the reaction of phenylboroinc acid and bromobenzene in the presence of UiO-66-Pyta-Pd resulted in $80 \%$ yield of biphenyl as the desired product after $2 \mathrm{~h}$. Under identical conditions, the use of UiO-66-Pyta afforded no product yield. When, UiO-66- $\mathrm{NH}_{2}-\mathrm{Pd}$ was employed as catalyst, only $30 \%$ yield of the desired product was obtained. These experiments suggest that the high catalytic activity of UiO-66-Ptya-Pd derives from the formation of the stable chelated palladium complex of pyta-Pd(II) (model $\mathbf{I}$ in

Figure 9), ${ }^{45,} 46$ demonstrating again the potential of UiO-66-Ptya to adsorb Pd(II). Notably, the nominal MOF catalyst showed excellent recyclability without losing its activity for up to three runs (Table S2). The recovered catalyst showed no structural changes after being used as catalyst respect to the fresh one as evidenced by SEM (Fig. 4, Fig. S14 and Fig. S18). Furthermore, ICPAES analysis of the reaction filtrate obtained after the completion reaction indicated only a very negligible amount of Pd species.

\section{Conclusions}

In this study, for the first time, we synthesized a robust and porous UiO-66-based MOF, UiO-66-Pyta from UiO-66- $\mathrm{NH}_{2}$ through the three PSMs. The UiO-66-Pyta was applied for highly efficient and selective adsorption of palladium, as a heavy metal, from a solution containing other ions. Adsorption measurements showed that UiO-66-Pyta performs better than other sorbents to remove trace metal amounts and the pyta ligand, $\mathrm{Zr}-\mathrm{OH}$, residual azide groups and aromatic rings are all contributing to the adsorption performance of UiO-66-Pyta for Pd(II). XPS analysis and DFT calculations clearly confirmed the prevalent role of the Pyta ligand for the 
efficient and selective binding of Pd(II) ions. The complexation of Pd(II) with Ptya renders UiO66-Pyta-Pd as a heterogeneous and reusable catalyst for an important organic transformation such as the SuzukiMiyaura cross-coupling reaction. The cooperative process (heavy metals in real samples $\rightarrow$ adsorption $\rightarrow$ catalysis) offered in this work opens up a new direction for waste water treatment and water purification. The highly performance and stability of the MOF in the heavy metal adsorption, less amount of the used sorbent, and short time of the process indicate the material as good candidate for industrial and sustainable applications.

\section{ASSOCIATED CONTENT}

\section{Supporting Information}

Additional information on the physical and spectral data (NMR spectra, TGA profiles, Zeta potential, FT-IR spectra, PXRD patterns, SEM images, EDS analyses, and XPS spectra), and more adsorption experiments (effect of amount of adsorbent, effect of eluent concentration, tolerance limits of MOF adsorbent, and effect of salt addition) are available in the Supporting Information.

\section{Corresponding Authors}

Email address: hgarcia@qim.upv.es (H.García), Tel: +34-96-387-7807;

Email address: alir.oveisi@gmail.com (A.R.Oveisi), Tel: +98-915-542-8132;

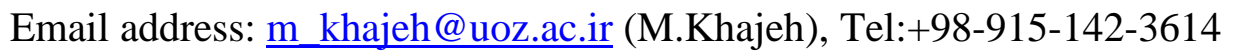

\section{Author Contributions}


The research was conceived by all the authors. All authors have given approval to the final version of the manuscript.

\section{Note}

The authors declare no competing financial interests.

\section{ACKNOWLEDGMENT}

Authors gratefully acknowledge the financial support for this work from the Politécnica de Valencia, Valencia, Spain. Also, financial support by the University of Zabol is gratefully acknowledged (Grant NO.: UOZ-GR-9517-1 \& UOZ-GR-9618-53).

\section{REFERENCES}

1. Zereini, F.; Alt, F., Palladium Emissions in the Environment: Analytical Methods, Environmental Assessment and Health Effects. Springer: 2006.

2. Rao, C. R. M.; Reddi, G. S., Platinum Group Metals (PGM); Occurrence, Use and Recent Trends in Their Determination. TrAC, Trends Anal. Chem. 2000, 19 (9), 565-586.

3. Sharma, S.; Krishna Kumar, A. S.; Rajesh, N., A Perspective on Diverse Adsorbent Materials to Recover Precious Palladium and the Way Forward. RSC Adv. 2017, 7 (82), 52133-52142.

4. Crundwell, F. K.; Moats, M. S.; Ramachandran, V.; Robinson, T. G.; Davenport, W. G., Chapter 31 Platinum-Group Metals, Production, Use and Extraction Costs. In Extractive Metallurgy of Nickel, Cobalt and Platinum Group Metals, Crundwell, F. K.; Moats, M. S.; Ramachandran, V.; Robinson, T. G.; Davenport, W. G., Eds. Elsevier: Oxford, 2011; pp 395-409.

5. Cieszynska, A.; Wieczorek, D., Extraction and Separation of Palladium(II), Platinum(IV), Gold(III) and Rhodium(III) Using Piperidine-Based Extractants. Hydrometallurgy 2018, 175, 359-366.

6. Ghezzi, L.; Robinson, B. H.; Secco, F.; Tiné, M. R.; Venturini, M., Removal and Recovery of Palladium(II) Ions from Water Using Micellar-Enhanced Ultrafiltration with a Cationic Surfactant. Colloids Surf., A 2008, 329 (1), 12-17.

7. Mahmoud, A.; Hoadley, A. F. A., An Evaluation of a Hybrid Ion Exchange Electrodialysis Process in the Recovery of Heavy Metals from Simulated Dilute Industrial Wastewater. Water Res. 2012, 46 (10), 3364-3376.

8. Fotovat, H.; Khajeh, M.; Oveisi, A. R.; Ghaffari-Moghaddam, M.; Daliran, S., A Hybrid Material Composed of an Amino-Functionalized Zirconium-Based Metal-Organic Framework and a UreaBased Porous Organic Polymer as an Efficient Sorbent for Extraction of Uranium(VI). Microchim. Acta 2018, 185 (10), 469.

9. Serencam, H.; Bulut, V. N.; Tufekci, M.; Gundogdu, A.; Duran, C.; Hamza, S.; Soylak, M., Separation and Pre-Concentration of Palladium(II) from Environmental and Industrial Samples by Formation of a 
Derivative of 1,2,4-Triazole Complex on Amberlite Xad-2010 Resin. Int. J. Environ. Anal. Chem. 2013, 93 (14), 1484-1499.

10.Soylak, M.; Elci, L.; Dogan, M., A Sorbent Extraction Procedure for the Preconcentration of Gold, Silver and Palladium on an Activated Carbon Column. Anal. Lett. 2000, 33 (3), 513-525.

11.Zhou, L.; Xu, J.; Liang, X.; Liu, Z., Adsorption of Platinum(IV) and Palladium(II) from Aqueous Solution by Magnetic Cross-Linking Chitosan Nanoparticles Modified with Ethylenediamine. J. Hazard. Mater. 2010, 182 (1), 518-524.

12.Liu, L.; Li, C.; Bao, C.; Jia, Q.; Xiao, P.; Liu, X.; Zhang, Q., Preparation and Characterization of Chitosan/Graphene Oxide Composites for the Adsorption of $\mathrm{Au}(\mathrm{III})$ and Pd(II). Talanta 2012, 93, 350-357.

13.Liu, L.; Liu, S.; Zhang, Q.; Li, C.; Bao, C.; Liu, X.; Xiao, P., Adsorption of Au(III), Pd(II), and Pt(IV) from Aqueous Solution onto Graphene Oxide. J. Chem. Eng. Data 2013, 58 (2), 209-216.

14. Awual, M. R.; Khaleque, M. A.; Ratna, Y.; Znad, H., Simultaneous Ultra-Trace Palladium(II) Detection and Recovery from Wastewater Using New Class Meso-Adsorbent. J. Ind. Eng. Chem. 2015, 21, 405-413.

15.Sharma, S.; Wu, C.-M.; Koodali, R. T.; Rajesh, N., An Ionic Liquid-Mesoporous Silica Blend as a Novel Adsorbent for the Adsorption and Recovery of Palladium Ions, and Its Applications in Continuous Flow Study and as an Industrial Catalyst. RSC Adv. 2016, 6 (32), 26668-26678.

16.Lin, S.; Kumar Reddy, D. H.; Bediako, J. K.; Song, M.-H.; Wei, W.; Kim, J.-A.; Yun, Y.-S., Effective Adsorption of $\mathrm{Pd}(\mathrm{II}), \mathrm{Pt}(\mathrm{IV})$ and $\mathrm{Au}(\mathrm{III})$ by $\mathrm{Zr}(\mathrm{IV})$-Based Metal-Organic Frameworks from Strongly Acidic Solutions. J. Mater. Chem. A 2017, 5 (26), 13557-13564.

17.Han, X.; Yang, S.; Schröder, M., Porous Metal-Organic Frameworks as Emerging Sorbents for Clean Air. Nat. Rev. Chem. 2019, 3 (2), 108-118.

18.Chen, Z.; Hanna, S. L.; Redfern, L. R.; Alezi, D.; Islamoglu, T.; Farha, O. K., Reticular Chemistry in the Rational Synthesis of Functional Zirconium Cluster-Based Mofs. Coord. Chem. Rev. 2019, 386, 32-49.

19.Rogge, S. M. J.; Bavykina, A.; Hajek, J.; Garcia, H.; Olivos-Suarez, A. I.; Sepúlveda-Escribano, A.; Vimont, A.; Clet, G.; Bazin, P.; Kapteijn, F.; Daturi, M.; Ramos-Fernandez, E. V.; Llabrés i Xamena, F. X.; Van Speybroeck, V.; Gascon, J., Metal-Organic and Covalent Organic Frameworks as SingleSite Catalysts. Chem. Soc. Rev. 2017, 46 (11), 3134-3184.

20.Daliran, S.; Santiago-Portillo, A.; Navalón, S.; Oveisi, A. R.; Álvaro, M.; Ghorbani-Vaghei, R.; Azarifar, D.; García, H., Cu(II)-Schiff Base Covalently Anchored to MIL-125(Ti)- $\mathrm{NH}_{2}$ as Heterogeneous Catalyst for Oxidation Reactions. J. Colloid Interface Sci. 2018, 532, 700-710.

21.Yin, Z.; Wan, S.; Yang, J.; Kurmoo, M.; Zeng, M.-H., Recent Advances in Post-Synthetic Modification of Metal-Organic Frameworks: New Types and Tandem Reactions. Coord. Chem. Rev. 2019, 378, 500-512.

22.Tchalala, M. R.; Bhatt, P. M.; Chappanda, K. N.; Tavares, S. R.; Adil, K.; Belmabkhout, Y.; Shkurenko, A.; Cadiau, A.; Heymans, N.; De Weireld, G.; Maurin, G.; Salama, K. N.; Eddaoudi, M., Fluorinated Mof Platform for Selective Removal and Sensing of $\mathrm{SO}_{2}$ from Flue Gas and Air. Nat. Commun. 2019, 10 (1), 1328.

23.Zha, M.; Liu, J.; Wong, Y.-L.; Xu, Z., Extraction of Palladium from Nuclear Waste-Like Acidic Solutions by a Metal-Organic Framework with Sulfur and Alkene Functions. J. Mater. Chem. A 2015, 3 (7), 3928-3934.

24.Yuan, N.; Pascanu, V.; Huang, Z.; Valiente, A.; Heidenreich, N.; Leubner, S.; Inge, A. K.; Gaar, J.; Stock, N.; Persson, I.; Martín-Matute, B.; Zou, X., Probing the Evolution of Palladium Species in Pd@MOF Catalysts During the Heck Coupling Reaction: An Operando X-Ray Absorption Spectroscopy Study. J. Am. Chem. Soc. 2018, 140 (26), 8206-8217.

25.Dhakshinamoorthy, A.; Li, Z.; Garcia, H., Catalysis and Photocatalysis by Metal Organic Frameworks. Chem. Soc. Rev. 2018, 47 (22), 8134-8172.

26.Xiao, J.-D.; Jiang, H.-L., Metal-Organic Frameworks for Photocatalysis and Photothermal Catalysis. Acc. Chem. Res. 2019, 52 (2), 356-366. 
27.Sun, D.; Ye, L.; Li, Z., Visible-Light-Assisted Aerobic Photocatalytic Oxidation of Amines to Imines over $\mathrm{NH}_{2}$-MIL-125(Ti). Appl. Catal., B 2015, 164, 428-432.

28.Rojas, S.; Arenas-Vivo, A.; Horcajada, P., Metal-Organic Frameworks: A Novel Platform for Combined Advanced Therapies. Coord. Chem. Rev. 2019, 388, 202-226.

29.Bobbitt, N. S.; Mendonca, M. L.; Howarth, A. J.; Islamoglu, T.; Hupp, J. T.; Farha, O. K.; Snurr, R. Q., Metal-Organic Frameworks for the Removal of Toxic Industrial Chemicals and Chemical Warfare Agents. Chem. Soc. Rev. 2017, 46 (11), 3357-3385.

30.Rojas, S.; Baati, T.; Njim, L.; Manchego, L.; Neffati, F.; Abdeljelil, N.; Saguem, S.; Serre, C.; Najjar, M. F.; Zakhama, A.; Horcajada, P., Metal-Organic Frameworks as Efficient Oral Detoxifying Agents. J. Am. Chem. Soc. 2018, 140 (30), 9581-9586.

31.Yuan, S.; Qin, J.-S.; Lollar, C. T.; Zhou, H.-C., Stable Metal-Organic Frameworks with Group 4 Metals: Current Status and Trends. ACS Cent. Sci. 2018, 4 (4), 440-450.

32.Bai, Y.; Dou, Y.; Xie, L.-H.; Rutledge, W.; Li, J.-R.; Zhou, H.-C., Zr-Based Metal-Organic Frameworks: Design, Synthesis, Structure, and Applications. Chem. Soc. Rev. 2016, 45 (8), 23272367.

33.Knapp, J. G.; Zhang, X.; Elkin, T.; Wolfsberg, L. E.; Hanna, S. L.; Son, F. A.; Scott, B. L.; Farha, O. K., Single Crystal Structure and Photocatalytic Behavior of Grafted Uranyl on the Zr-Node of a Pyrene-Based Metal-Organic Framework. CrystEngComm 2020, 22, 2097-2102.

34.Howarth, A. J.; Katz, M. J.; Wang, T. C.; Platero-Prats, A. E.; Chapman, K. W.; Hupp, J. T.; Farha, O. K., High Efficiency Adsorption and Removal of Selenate and Selenite from Water Using MetalOrganic Frameworks. J. Am. Chem. Soc. 2015, 137 (23), 7488-7494.

35.Drout, R. J.; Howarth, A. J.; Otake, K.-i.; Islamoglu, T.; Farha, O. K., Efficient Extraction of Inorganic Selenium from Water by a Zr Metal-Organic Framework: Investigation of Volumetric Uptake Capacity and Binding Motifs. CrystEngComm 2018, 20 (40), 6140-6145.

36.Audu, C. O.; Nguyen, H. G. T.; Chang, C.-Y.; Katz, M. J.; Mao, L.; Farha, O. K.; Hupp, J. T.; Nguyen, S. T., The Dual Capture of Asv and Asiii by UiO-66 and Analogues. Chem. Sci. 2016, 7 (10), 6492-6498.

37.Kobielska, P. A.; Howarth, A. J.; Farha, O. K.; Nayak, S., Metal-Organic Frameworks for Heavy Metal Removal from Water. Coord. Chem. Rev. 2018, 358, 92-107.

38.Ali Akbar Razavi, S.; Morsali, A., Linker Functionalized Metal-Organic Frameworks. Coord. Chem. Rev. 2019, 399, 213023.

39.Moghaddam, Z. S.; Kaykhaii, M.; Khajeh, M.; Oveisi, A. R., Synthesis of UiO-66-Oh Zirconium Metal-Organic Framework and Its Application for Selective Extraction and Trace Determination of Thorium in Water Samples by Spectrophotometry. Spectrochim. Acta, Part A 2018, 194, 76-82.

40.Chang, Z.; Li, F.; Qi, X.; Jiang, B.; Kou, J.; Sun, C., Selective and Efficient Adsorption of Au(III) in Aqueous Solution by Zr-Based Metal-Organic Frameworks (Mofs): An Unconventional Way for Gold Recycling. J. Hazard. Mater. 2020, 391, 122175.

41.Yee, K.-K.; Reimer, N.; Liu, J.; Cheng, S.-Y.; Yiu, S.-M.; Weber, J.; Stock, N.; Xu, Z., Effective Mercury Sorption by Thiol-Laced Metal-Organic Frameworks: In Strong Acid and the Vapor Phase. J. Am. Chem. Soc. 2013, 135 (21), 7795-7798.

42.Fu, L.; Wang, S.; Lin, G.; Zhang, L.; Liu, Q.; Zhou, H.; Kang, C.; Wan, S.; Li, H.; Wen, S., PostModification of Uio-66-Nh2 by Resorcyl Aldehyde for Selective Removal of $\mathrm{Pb}(\mathrm{II})$ in Aqueous Media. J. Clean. Prod. 2019, 229, 470-479.

43.Saleem, H.; Rafique, U.; Davies, R. P., Investigations on Post-Synthetically Modified UiO-66- $\mathrm{NH}_{2}$ for the Adsorptive Removal of Heavy Metal Ions from Aqueous Solution. Micropor. Mesopor. Mat. 2016, 221, 238-244.

44.Peng, Y.; Huang, H.; Zhang, Y.; Kang, C.; Chen, S.; Song, L.; Liu, D.; Zhong, C., A Versatile MOFBased Trap for Heavy Metal Ion Capture and Dispersion. Nat. Commun. 2018, 9 (1), 187.

45.Jindabot, S.; Teerachanan, K.; Thongkam, P.; Kiatisevi, S.; Khamnaen, T.; Phiriyawirut, P.; Charoenchaidet, S.; Sooksimuang, T.; Kongsaeree, P.; Sangtrirutnugul, P., Palladium(II) Complexes 
Featuring Bidentate Pyridine-Triazole Ligands: Synthesis, Structures, and Catalytic Activities for Suzuki-Miyaura Coupling Reactions. J. Organomet. Chem. 2014, 750, 35-40.

46.Ervithayasuporn, V.; Kwanplod, K.; Boonmak, J.; Youngme, S.; Sangtrirutnugul, P., Homogeneous and Heterogeneous Catalysts of Organopalladium Functionalized-Polyhedral Oligomeric Silsesquioxanes for Suzuki-Miyaura Reaction. J. Catal. 2015, 332, 62-69.

47.Pintado-Sierra, M.; Rasero-Almansa, A. M.; Corma, A.; Iglesias, M.; Sánchez, F., Bifunctional Iridium-(2-Aminoterephthalate)-Zr-Mof Chemoselective Catalyst for the Synthesis of Secondary Amines by One-Pot Three-Step Cascade Reaction. J. Catal. 2013, 299, 137-145.

48.Zhao, Y.; Truhlar, D. G., The M06 Suite of Density Functionals for Main Group Thermochemistry, Thermochemical Kinetics, Noncovalent Interactions, Excited States, and Transition Elements: Two New Functionals and Systematic Testing of Four M06-Class Functionals and 12 Other Functionals. Theor. Chem. Acc. 2008, 120 (1), 215-241.

49.Zhao, Y.; Truhlar, D. G., Design of Density Functionals That Are Broadly Accurate for Thermochemistry, Thermochemical Kinetics, and Nonbonded Interactions. J. Phys. Chem. A 2005, 109 (25), 5656-5667.

50.Frisch, M. J.; Trucks, G. W.; Schlegel, H. B.; Scuseria, G. E.; Robb, M. A.; Cheeseman, J. R.; Scalmani, G.; Barone, V.; Petersson, G. A.; Nakatsuji, H.; Li, X.; Caricato, M.; Marenich, A. V.; Bloino, J.; Janesko, B. G.; Gomperts, R.; Mennucci, B.; Hratchian, H. P.; Ortiz, J. V.; Izmaylov, A. F.; Sonnenberg, J. L.; Williams; Ding, F.; Lipparini, F.; Egidi, F.; Goings, J.; Peng, B.; Petrone, A.; Henderson, T.; Ranasinghe, D.; Zakrzewski, V. G.; Gao, J.; Rega, N.; Zheng, G.; Liang, W.; Hada, M.; Ehara, M.; Toyota, K.; Fukuda, R.; Hasegawa, J.; Ishida, M.; Nakajima, T.; Honda, Y.; Kitao, O.; Nakai, H.; Vreven, T.; Throssell, K.; Montgomery Jr., J. A.; Peralta, J. E.; Ogliaro, F.; Bearpark, M. J.; Heyd, J. J.; Brothers, E. N.; Kudin, K. N.; Staroverov, V. N.; Keith, T. A.; Kobayashi, R.; Normand, J.; Raghavachari, K.; Rendell, A. P.; Burant, J. C.; Iyengar, S. S.; Tomasi, J.; Cossi, M.; Millam, J. M.; Klene, M.; Adamo, C.; Cammi, R.; Ochterski, J. W.; Martin, R. L.; Morokuma, K.; Farkas, O.; Foresman, J. B.; Fox, D. J. Gaussian 09 Rev. A.02, Wallingford, CT, 2009.

51.Hay, P. J.; Wadt, W. R., Ab Initio Effective Core Potentials for Molecular Calculations. Potentials for the Transition Metal Atoms Sc to Hg. J. Chem. Phys. 1985, 82 (1), 270-283.

52.Hay, P. J.; Wadt, W. R., Ab Initio Effective Core Potentials for Molecular Calculations. Potentials for K to Au Including the Outermost Core Orbitals. J. Chem. Phys. 1985, 82 (1), 299-310.

53.Azarifar, D.; Ghorbani-Vaghei, R.; Daliran, S.; Oveisi, A. R., A Multifunctional Zirconium-Based Metal-Organic Framework for the One-Pot Tandem Photooxidative Passerini Three-Component Reaction of Alcohols. ChemCatChem 2017, 9 (11), 1992-2000.

54.Wang, X.; Chen, W.; Zhang, L.; Yao, T.; Liu, W.; Lin, Y.; Ju, H.; Dong, J.; Zheng, L.; Yan, W.; Zheng, X.; Li, Z.; Wang, X.; Yang, J.; He, D.; Wang, Y.; Deng, Z.; Wu, Y.; Li, Y., Uncoordinated Amine Groups of Metal-Organic Frameworks to Anchor Single Ru Sites as Chemoselective Catalysts toward the Hydrogenation of Quinoline. J. Am. Chem. Soc. 2017, 139 (28), 9419-9422.

55.Cavka, J. H.; Jakobsen, S.; Olsbye, U.; Guillou, N.; Lamberti, C.; Bordiga, S.; Lillerud, K. P., A New Zirconium Inorganic Building Brick Forming Metal Organic Frameworks with Exceptional Stability. J. Am. Chem. Soc. 2008, 130 (42), 13850-13851.

56.Liang, H. F.; Wang, Z. C., Adsorption of Bovine Serum Albumin on Functionalized Silica-Coated Magnetic Mnfe2o4 Nanoparticles. Mater. Chem. Phys. 2010, 124 (2), 964-969.

57.Wu, R.; Qu, J.; Chen, Y., Magnetic Powder $\mathrm{MnO}-\mathrm{Fe}_{2} \mathrm{O}_{3}$ Composite-a Novel Material for the Removal of Azo-Dye from Water. Water Res. 2005, 39 (4), 630-638.

58.Tan, Y.; Wang, K.; Yan, Q.; Zhang, S.; Li, J.; Ji, Y., Synthesis of Amino-Functionalized Waste Wood Flour Adsorbent for High-Capacity Pb(II) Adsorption. ACS Omega 2019, 4 (6), 10475-10484.

59.Howarth, A. J.; Liu, Y.; Hupp, J. T.; Farha, O. K., Metal-Organic Frameworks for Applications in Remediation of Oxyanion/Cation-Contaminated Water. CrystEngComm 2015, 17 (38), 7245-7253.

60.Nagarjuna, R.; Sharma, S.; Rajesh, N.; Ganesan, R., Effective Adsorption of Precious Metal Palladium over Polyethyleneimine-Functionalized Alumina Nanopowder and Its Reusability as a Catalyst for Energy and Environmental Applications. ACS Omega 2017, 2 (8), 4494-4504. 
61.Veerakumar, P.; Thanasekaran, P.; Lu, K.-L.; Liu, S.-B.; Rajagopal, S., Functionalized Silica Matrices and Palladium: A Versatile Heterogeneous Catalyst for Suzuki, Heck, and Sonogashira Reactions. ACS Sustain. Chem. Eng. 2017, 5 (8), 6357-6376.

62.Singuru, R.; Dhanalaxmi, K.; Shit, S. C.; Reddy, B. M.; Mondal, J., Palladium Nanoparticles Encaged in a Nitrogen-Rich Porous Organic Polymer: Constructing a Promising Robust Nanoarchitecture for Catalytic Biofuel Upgrading. ChemCatChem 2017, 9 (13), 2550-2564.

63.Liu, J.; Hao, J.; Hu, C.; He, B.; Xi, J.; Xiao, J.; Wang, S.; Bai, Z., Palladium Nanoparticles Anchored on Amine-Functionalized Silica Nanotubes as a Highly Effective Catalyst. J. Phys. Chem. C 2018, 122 (5), 2696-2703.

64.Fortgang, P.; Tite, T.; Barnier, V.; Zehani, N.; Maddi, C.; Lagarde, F.; Loir, A.-S.; Jaffrezic-Renault, N.; Donnet, C.; Garrelie, F.; Chaix, C., Robust Electrografting on Self-Organized 3d Graphene Electrodes. ACS Appl. Mater. Interfaces 2016, 8 (2), 1424-1433.

65.Bi, F.; Zhang, X.; Chen, J.; Yang, Y.; Wang, Y., Excellent Catalytic Activity and Water Resistance of Uio-66-Supported Highly Dispersed Pd Nanoparticles for Toluene Catalytic Oxidation. Appl. Catal., B 2020, 269, 118767.

66.Jiang, D.; Fang, G.; Tong, Y.; Wu, X.; Wang, Y.; Hong, D.; Leng, W.; Liang, Z.; Tu, P.; Liu, L.; Xu, K.; Ni, J.; Li, X., Multifunctional Pd@UiO-66 Catalysts for Continuous Catalytic Upgrading of Ethanol to N-Butanol. ACS Catal. 2018, 8 (12), 11973-11978.

67.Nguyen, H. G. T.; Mao, L.; Peters, A. W.; Audu, C. O.; Brown, Z. J.; Farha, O. K.; Hupp, J. T.; Nguyen, S. T., Comparative Study of Titanium-Functionalized Uio-66: Support Effect on the Oxidation of Cyclohexene Using Hydrogen Peroxide. Catal. Sci. Technol. 2015, 5 (9), 4444-4451.

68.Wang, C.; Liu, X.; Chen, J. P.; Li, K., Superior Removal of Arsenic from Water with Zirconium Metal-Organic Framework Uio-66. Sci. Rep. 2015, 5 (1), 16613.

69. Manna, K.; Ji, P.; Lin, Z.; Greene, F. X.; Urban, A.; Thacker, N. C.; Lin, W., Chemoselective SingleSite Earth-Abundant Metal Catalysts at Metal-Organic Framework Nodes. Nat. Commun. 2016, 7 (1), 12610.

70.Pearson, R. G., Hard and Soft Acids and Bases. J. Am. Chem. Soc 1963, 85 (22), 3522-3539. 


\section{Table of Contents}

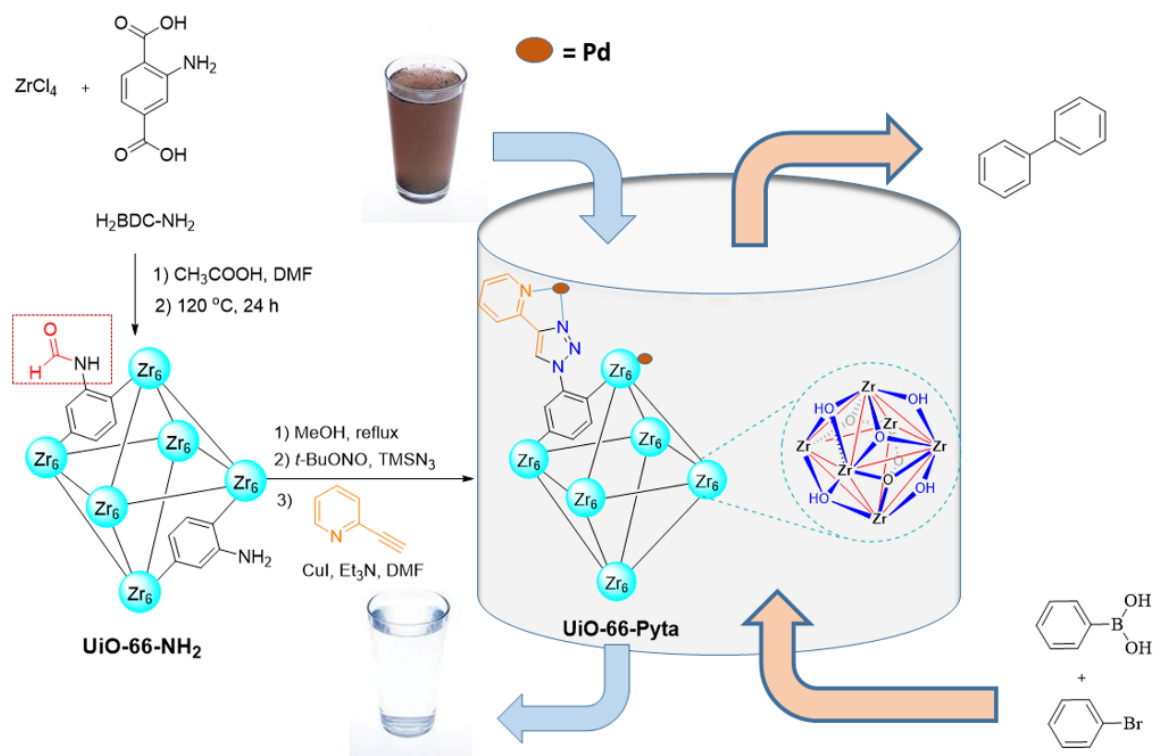

